\title{
Out-of-Home Care Placements of Children and Adolescents Born Preterm: A Register-Based Cohort Study
}

Short title: Preterm Birth and Risk of Out-of-Home Care Placement

Suvi Alenius, ${ }^{1,2}$ Eero Kajantie, ${ }^{1,2,3,4}$ Reijo Sund, ${ }^{5,6}$ Markku Nurhonen, ${ }^{1}$

Pieta Näsänen-Gilmore, ${ }^{1}$ Marja Vääräsmäki, ${ }^{1,3}$ Mika Gissler, ${ }^{1,7}$ Petteri Hovi, ${ }^{1,2}$

\begin{abstract}
Affiliations
${ }^{1}$ Finnish Institute for Health and Welfare, Helsinki and Oulu, Finland;

${ }^{2}$ Children's Hospital, University of Helsinki and Helsinki University Hospital, Helsinki, Finland;

${ }^{3}$ Faculty of Medicine, PEDEGO Research Unit, MRC Oulu, Oulu University Hospital and University of Oulu, Oulu, Finland;

${ }^{4}$ Department of Clinical and Molecular Medicine, Norwegian University of Science and Technology, Trondheim, Norway;

${ }^{5}$ Faculty of Health Sciences, School of Medicine, Institute of Clinical Medicine, University of Eastern Finland, Kuopio, Finland;

${ }^{6}$ Faculty of Social Sciences, Centre for Research Methods, University of Helsinki, Helsinki, Finland;

${ }^{7}$ Karolinska Institute, Department of Neurobiology, Care Sciences and Society, Division of Family Medicine, Stockholm, Sweden
\end{abstract}

\section{Correspondence}

Suvi Alenius

Finnish Institute for Health and Welfare

Department of Public Health Solutions

Helsinki, Finland

Email:suvi.alenius@thl.fi 


\section{Social media quote}

A dose-response relationship between a shorter length of gestation and out-of-home care placement risk exists. Risk is higher for early and late preterm and early term children in comparison to their full term born peers. Preterm children are also younger at first entry to care.
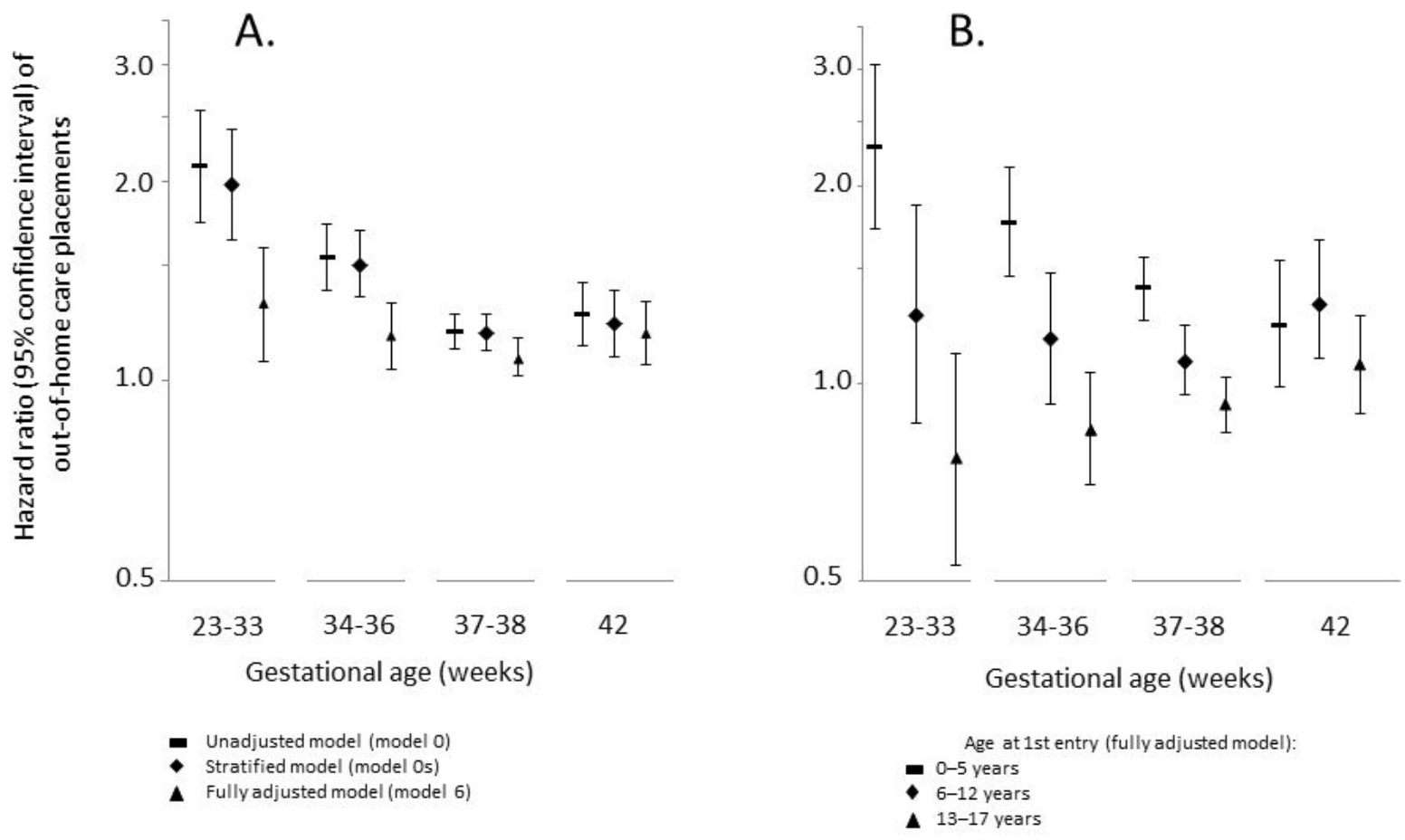

Facebook: https://www.facebook.com/suvi.turkka 


\section{Synopsis}

\section{Study Question}

- The contribution of gestational age to the likelihood of out-of-home care $(\mathrm{OHC})$ placement(s) and, particularly, to the child's age at first entry is unknown. It also remains unclear regarding the extent to which the association amongst gestational age, $\mathrm{OHC}$ placement risk and age at first $\mathrm{OHC}$ placement is explained by shared common risk factors for both preterm birth and $\mathrm{OHC}$.

\section{What's already known}

- Previous studies suggest that preterm birth predisposes to $\mathrm{OHC}$ as a form of child protection action.

\section{What this study adds}

- $\mathrm{OHC}$ placements are more common among preterm and early term children, in comparison to those born full term, and occur at a younger age. Earlier gestational age and higher $\mathrm{OHC}$ placement risk may partly reflect the unfavourable pre- and postnatal circumstances that tend to accumulate especially among preterm children. 


\section{ABSTRACT}

Background: Preterm birth predisposes to child protection action in the form out-of-home care.

Objective: To study the impact of the degree of preterm birth on the likelihood for OHC placement(s) and their timing.

Methods: This population-based register-linkage study assessed the likelihood of OHC placement in different gestational age groups using multivariable Cox regression models. All 193033 traceable singletons (8324 preterm, 4.3\%) live-born in Finland (January 1987 - September 1990), as the first index child of each mother within the cohort period, were followed up until their $18^{\text {th }}$ birthday.

Results: 6562 children (3.4\%) experienced OHC. In comparison to full term children (39-41 weeks), those born at 23-33 completed weeks were predisposed to OHC (hazard ratio [HR] 2.11, 95\% confidence interval $[\mathrm{Cl}] 1.74,2.56)$. For those born late preterm (34-36 weeks) and early term (37-38 weeks), the HRs were 1.54 (95\% Cl 1.37, 1.73) and 1.19 (95\% Cl 1.12, 1.26), respectively. Adjustment for parental and child characteristics attenuated the HRs: $23-33$ weeks: 1.31 (95\% Cl 1.07, 1.59), 34-36 weeks 1.17 (95\% Cl 1.04, 1.31) and 37-38 weeks 1.08 (95\% Cl 1.02, 1.16). However, the adjusted HRs for first $\mathrm{OHC}$ entries at 0-5 years of age were higher: 23-33 weeks 2.29 (95\% Cl 1.72, 3.05), 34-36 weeks 1.76 (95\% Cl 1.46, 2.13) and 37-38 weeks 1.40 (95\% Cl 1.25, 1.56). Among those born preterm or early term, in comparison to their term born peers, no excess risk for $\mathrm{OHC}$ was seen after five years.

Conclusions: A dose-response relationship exists between the level of preterm birth and $\mathrm{OHC}$ placement risk. OHC placements are more common among early and late preterm, and early term 
children, compared with those born full term, and occur at younger age. Perinatal and postnatal adverse circumstances appear to explain the phenomenon only partly. 


\section{Keywords}

preterm birth; gestational age; cohort studies; child protective services; foster home care; foster children

Word count: 3365 


\section{BACKGROUND}

Approximately $11 \%$ of all live-born infants worldwide are born preterm (at less than 37 completed weeks of gestation). ${ }^{1}$ Irrespective of the reason for preterm birth, it may place a long-lasting burden on the childhood family of the preterm child. Families of children born preterm or at very low birthweight (VLBW) $(<1500$ g) or at extremely low birthweight (ELBW) (<1000 g) appear to have fewer subsequent children, more parenting stress, and poorer parental emotional health, compared with families of term born children..$^{2-5}$ Moreover, preterm children appear more likely to experience child protection actions ${ }^{6}$ such as out-of-home care placements (OHC placement, also known as foster care). ${ }^{7-9}$ Studies assessing the association of preterm birth and low birthweight on child maltreatment have reported increased risk among preterm and low-birthweight children, ${ }^{10-12}$ although contradicting results have also been reported. ${ }^{13,14}$

Even if the association between preterm birth in general and $\mathrm{OHC}$ placements seems fairly well established, ${ }^{7-9}$ it is unknown whether the higher risk of those who are born preterm is limited to infancy and early childhood or whether it is also present in adolescence, when OHC placements again peak, ${ }^{7}$ and to what extent this higher risk is explained by parental characteristics that predispose to preterm birth and child protection actions. Furthermore, whether this risk varies according to the degree of preterm birth remains unassessed. In this register-linkage study, we were able to assess this by linking population-wide data from administrative registers and to place a special emphasis on common shared risk factors for preterm birth and OHC placement(s). We suggest that preterm birth of a child and the related extra parental burden may vary according to the gestational age of the child, which in turn may be reflected in the OHC entry rates and the timing of first entries. 


\section{METHODS}

\section{Data sources}

The data originated from six national registers, namely: (i) the Medical Birth Register (MBR); (ii) the Central Population Register (CPR); (iii) the Register of Congenital Malformations (RCM); (iv) the Care Register for Health Care (CRHC); (v) the Child Welfare Register (CWR); and (vi) the Census Register. The CWR, maintained by the Finnish Institute for Health and Welfare (THL), and the Census Register, maintained by Statistics Finland are described in Supplementary Material. Other registers and the validity of their data are described in detail elsewhere. ${ }^{2}$

\section{Cohort members}

A total of 235622 children with a valid personal identity code ( $99.8 \%$ of all live-born children) born in Finland between January 1, 1987 and September 30, 1990 (see Supplementary Material) were first identified from the MBR and served as index children. From this group, we excluded children born from multiple pregnancies (2.2\%). Of the 230308 singleton live-born index children, 3848 (1.7\%) were alternatively excluded due to either missing or illogical data on their gestational age or birthweight standard deviation score (SDS). SDS was considered illogical if it was $\leq-6.0$, or, among preterm children, >3.0. Birthweight standard deviations were calculated using the current national birthweight standards for gestational weeks of $23-43 .{ }^{15}$ The Central Population Register enabled the identification of fathers (98.7\%) and siblings of the index children who had the same biological mother as the index child. Data on parental socioeconomic position, SEP (updated through December 2014), and data from RCM (January 2015), CRCH (December 2012) and CWR (September 2008) were merged to these data by using encrypted personal identification codes that allow precise individual linkages between registers. Figure 1 describes the cohort. As a total of 33427 (14.8\%) mothers had several index children within the cohort, only the firstborn index 
children within the cohort period $(n=193033)$ were included in the main analyses to avoid any bias due to repeated data.

\section{Exposure}

Gestational age of the index child was the exposure. It was assessed according to the best clinical estimate of the length of gestation at the birth of the index child (ultrasound and/or maternal last menstrual period), and divided into five subgroups: early preterm (23-33 full weeks), late preterm (34- 36 weeks), early term (37-38 weeks), full term (39-41 weeks, reference) and post term (42 weeks). Extremely preterm (23-27 weeks), very preterm (28-31 weeks) and moderately preterm (32-33 weeks) gestational age groups were combined to the early preterm group, in order to ensure a sufficient number of children for the analyses.

\section{Outcomes}

First $\mathrm{OHC}$ placement prior to the $18^{\text {th }}$ birthday of an index child served as a main outcome. This was assessed using Cox regression model, ${ }^{16}$ with age of the index child as the underlying timescale. Unadjusted and adjusted hazard ratios (HR) with 95\% confidence intervals ( $\mathrm{Cl}$ ) served as the effect measure.

We hypothesised that the age of a child at first entry to $\mathrm{OHC}$ may vary by the gestational age. Therefore, we estimated time-dependent HRs by utilizing the interaction terms calculated separately for five dummy-coded gestational age categories and a three-category time-dependent variable for the follow-up period with cut-off points at 6 and 13 years of age. Baseline timedependent hazard ratio was calculated for full term children, who served as the reference. 
In main analyses the index children were followed up from birth until they were placed into OHC (6562; 3.4\%) or until they reached the age of 18 (191 444; 99.2\%). Children who emigrated (1009; $0.5 \%)$, died (1539; $0.8 \%)$ or whose both parents died $(223 ; 0.1 \%)$ were censored, according to whichever event took place first. The follow-up period varied from 0 days to 18.0 years and was rounded to the closest 30 days in the analyses, with the median follow-up time being 18.0 years (sum: 3.4 million person years).

Due to the time gap between the births of the cohort (1987 to 1990) and the establishment of the Child Welfare Register in 1991, we ran sensitivity analyses using the follow-up with a starting point at four years of age, as data on $\mathrm{OHC}$ placements is not complete for all index children within the cohort prior to that age. An additional sensitivity analysis assessed the sensitivity of the results on the potential unmeasured confounder of the association between the gestational age and the $\mathrm{OHC}$ placement (supplemental methods).

In supplemental analyses, conducted in order to validate the results of main analyses, propensity score matching (PSM) $)^{17,18}$ served as a tool to balance gestational age groups in terms of background characteristics. Information concerning the utilised PSM method is available in Supplementary Methods. Additionally, the effects of small for gestational age (SGA) status and the maternal socioeconomic position on the $\mathrm{OHC}$ placement risk according to gestational age category were assessed (supplemental methods). SGA was defined as infants with birthweight standard deviation score less than -2 . 


\section{Statistical analysis}

\section{Covariates}

All Cox regression analyses were stratified according to the birth year of an index child and to the maternal socioeconomic position (SEP) at the time of the child's birth. SEP was categorised as higher officials, lower officials, manual workers, and others. The same categorisation was later used for the paternal SEP. The maternal SEP was set as a covariate to stratify within the model allowing different baseline hazards for each SEP category, rather than adjusting for it, as it violated the Cox assumption for proportional hazards when used as a standard covariate; the tests based on the Schoenfeld residuals showed significant non-proportionality for the SEP categories.

Six models were fitted by adding variables in clusters. These models included (1) maternal age and marital status at the birth of the index child; (2) smoking in pregnancy and late onset of antenatal care; (3) the number of previous live-born children (biological and adoptive), the length of previous interbirth interval and urban residence; (4) the first maternal in-hospital treatment period for a psychiatric disorder as a time-dependent covariate; (5) child's sex, SGA, developmental disorder and/or intellectual disability, cerebral palsy and major birth anomaly; (6) paternal SEP and age at the child's birth. Supplementary methods (eFigures 1 and 2; eTable 1) present detailed information on the covariates. The decision to exclude parental deaths, a known risk factor for $\mathrm{OHC}^{7}$ from the models is shown in eTable 2 and eFigure 2.

SPSS 24 served as main statistical software (IBM Corp, Armonk, NY, USA). Additionally, in subanalyses, the IBM SPSS PS Matching plugin was utilised in propensity score matching. To examine the proportional hazard assumption, we employed R software (R Foundation for 
Statistical Computing, Vienna, Austria) version 3.50 with statistical code R packages 'survival' and 'survminer' to compute proportional hazard tests and visualise the Schoenfeld residuals.

\section{Missing data}

Among the 193012 women, the numbers of missing observations by covariate were as follows: $972(0.5 \%)$ for maternal marital status, $3812(2.0 \%)$ for smoking in pregnancy, $1573(0.8 \%)$ for the late onset of antenatal care, $1(0.0 \%)$ for the mode of delivery, and $1838(1.0 \%)$ for maternal SEP. Of the fathers $2233(1.2 \%)$ had no data on the SEP. A total of $95.4 \%$ of cases were complete. As the proportions of missing values in each of the variables was small ( $2.0 \%$ or less), and the sample size was large, we applied single imputation with most likely values (no data on smoking in pregnancy - did not smoke; no data on the late onset of antenatal care - did not participate late to antenatal care; no data on maternal marital status - was unmarried, no data on SEP - SEP category 'Other'). The variable on the mode of delivery was not included in the models. In sensitivity analysis mother and child dyads with missing data were excluded.

\section{Ethics approval}

The study was approved by applicable register authorities and the ethical approval for the study was granted by the local Ethics committees.

\section{RESULTS}

\section{Characteristics of the index children}

Table 1 and eTable 3 describe the characteristics of the index children and their parents per gestational age groups of the children. A total of 41315 (21.4\%) of the 193033 index children were born before 39 full weeks of gestation: $4.3 \%$ were preterm and $17.1 \%$ early term. Of all index 
children, 6562 (3.4\%) experienced OHC; preterm children were placed into $\mathrm{OHC}$ at a younger age than their full term born peers (Figure 2, eFigure 3). Developmental and intellectual disabilities, cerebral palsies, smallness for gestational age and major birth anomalies appeared more frequently among children born before 39 weeks of gestation, and especially among those born early preterm. A total of $1.4 \%$ of children did not have information on fatherhood registered to the CPR, among the preterm index children this percentage was 3.8.

\section{Characteristics of the parents}

Of the mothers, $2.0 \%$ had their first psychiatric in-hospital treatment period between Jan $1^{\text {st }}, 1969$ and the birth of the index child and $6.0 \%$ before the end of the follow-up. Of those mothers whose child was born preterm, 3.1\% had been hospitalized due to psychiatric disorder prior to the birth of the child, and $8.3 \%$ before the end of the follow-up. Corresponding percentages for mothers of full-term children were $1.9 \%$ and $5.7 \%$. Among the preterm index children mothers were more likely to be under 20 years or over 35 years of age at the birth of the child. Teenage parents were more common with a lower gestational age of the child, as were the parents with a lower SEP. Unmarried mothers and mothers initiating their prenatal visits later than at $22^{\text {nd }}$ weeks of gestation were also overrepresented among the preterm and early term children. Similarly, smoking in pregnancy and short interbirth intervals preceding the index child appeared to be more common among mothers of preterm or early term children.

\section{Gestational age and later placement to Out-of-Home Care}

There was no difference in the association between the gestational age and OHC placements between boys and girls ( $P$ for interaction $>.9$ ), therefore we report the results pooled for both sexes. 
Preterm index children had a higher overall risk for $\mathrm{OHC}$ placement, in comparison to their full term born peers (Figure 3a, eTable 4). The results of the final adjusted Cox regression analyses indicated that an adjustment for covariates, whose univariate associations for $\mathrm{OHC}$ placement are presented in eTable 5, had a considerable combined effect on gestational age groups impact on the $\mathrm{OHC}$ placement risk. They could not, however, completely explain the differences between the gestational age categories. Further analyses utilising the time-dependent variable for the followup period with cut-off points at 6 and 13 years of age revealed that the higher overall risk for OHC placement of those born preterm was explained by the preterm born children's increased risk for placement at the 0 to 5 years of age (Figure 3b, eTable 6).

\section{Sensitivity analyses}

The CWR provides complete data on OHC placements after January 1, 1991, but regarding placements before it, only those first placements that were followed by an $\mathrm{OHC}$ placement period after January 1, 1991 are available. As the partially incomplete OHC data during infancy and early childhood (see Supplementary Material) may affect the results, we ran the analyses by setting the onset of follow-up to four years of age. The overall risk of those born preterm or early term attenuated when compared with the main analysis (eTable 7). However, the specific risk for placement prior to six years of age remained (eTable 8).

We performed a sensitivity analysis to assess possible residual confounding, and found that potential for unmeasured confounders may exist. However, such confounding would require a relatively large association with both exposure and out-of-home placement (supplementary methods). Additionally, the results of the main analysis excluding mother and child dyads with missing data demonstrated similar point estimates (supplementary methods). 
The results of a subanalysis, in which we ignored any intra-mother correlation by including all 226439 mother-child pairs, were consistent with the results of the main analyses, indicating increasing HRs in relation to declining gestational age (eTables 9 and 10).

\section{Propensity Score Matching}

The results based on propensity score matched data confirm those of the main analyses (eTables 11 and 12, eFigure 4). The matched analyses indicated that an improved covariate balance across different gestational age categories may have resulted in a higher estimated $\mathrm{OHC}$ placement risk among preterm children.

\section{COMMENT}

\section{Principal findings}

In our nationwide cohort study of 193033 children, we assessed out-of-home care (OHC) placement(s) and the timing of the first $\mathrm{OHC}$ entries in preterm and early term born children. We placed particular weight on the effect of early, mainly mother-related, adverse circumstances. We found that preterm birth is not only associated with an increased risk for out-of-home care placement(s) but also that the more preterm the child is the higher the risk is. It is worthy to note that a moderately increased risk for $\mathrm{OHC}$ is also present in the large group of early term children. The higher risk for those born prior to 39 weeks' gestation is explained by the increased number of OHC placements before the age of six. The higher risk is only partly associated with maternal SEP at the birth of the index child and is mainly associated with a range of other adverse family characteristics that, however, explain only a part of the phenomenon. 


\section{Strengths of the study}

The main strength of the present study is the coverage of the nationwide data: it comprises all singleton live births within a 3.8-year period in Finland. The linkage of several population-wide registries provided longitudinal individual level data with minimal loss to follow-up. Timedependent Cox regression analyses allowed us to examine the changes in probabilities over time periods and the variation in follow-up time. As the Finnish population is ethnically homogeneous and only $0.8 \%$ of the Finnish population had an immigrant background in $1990,{ }^{19}$ the potential disparities in $\mathrm{OHC}$ placement risks among index children due to ethnic variation are likely to be small.

\section{Limitations of the data}

Due to the time gap between the births of the cohort and establishment of the Child Welfare Register, information on placements among children who were placed into OHC before January 1 , 1991, but never after that, was not available. The magnitude of the bias can be considered as moderate and to lead to underestimation of $\mathrm{OHC}$ placements at early childhood. Therefore, if we had complete data from January 1, 1987, then the disparities within gestational age categories and between the different models might have been more like the results of those analyses of our study, which utilises four years of age as the onset of the follow-up period. Unfortunately, the reasons for $\mathrm{OHC}$ placements are not recorded in the CWR. Furthermore, we lacked information about whether the estimation of the gestational age of the index child was based on maternal last menstrual period (LMP) or on foetal ultrasound. A previous study reported that $60 \%$ of the newborns in northern Finland had a gestational age estimate based on LMP during the 1985 to $1986,{ }^{20}$ and, as gestational age estimation based on LMP increases the estimated length of 
gestation, ${ }^{21}$ the rates of preterm births may have indeed decreased as a consequence. The effect of this on our results may, however, be considered as marginal.

\section{Interpretation}

This study does not entirely explain relationship between preterm birth and higher OHC placement risk. In addition to extra parental burden, other mechanisms could be contributing to the association between preterm birth and increased $\mathrm{OHC}$ placement risk especially at 0 to 5 years of age, as compared with full term born children: OHC entries of small children tend to associate with early adverse parental characteristics, ${ }^{6,22,23}$ which appeared to be accumulated among preterm children within our study, and explained part of the association. Furthermore, impaired parental-child bonding due to preterm birth could lead to increased rates of first OHC placements at an early age, at least among early preterm children. Current literature, however, does not universally support this explanation. ${ }^{24}$ Additionally, it may be possible that the evident association is, in part, explained by unrecognised factors or by the fact that the information on the gestational age of a child is not blinded from those who decide on the out-of-home care placement.

Few previous studies have assessed the effect of preterm birth on OHC placement risk and none of them take into account the level of preterm birth or the age at first placement. A populationbased study of all children born in Western Australia between 1990 and 2010 assessed preterm born children as one group. This study indicated a nearly 1.6-fold risk (HR 1.56, 95\% $\mathrm{Cl} 1.43,1.70$ ) for $\mathrm{OHC}$ placement, in comparison with children born at $37^{\text {th }}$ week of gestation or later, after adjustment for the sex, ethnicity, disability and birthweight for the gestational age of the child as well as for parental SEP, age and mental health or substance related admissions. ${ }^{8}$ Similarly, a Finnish study indicated a 1.4- to 1.5-fold risk for $\mathrm{OHC}$ placement among preterm-born children, 
again as one group, according to unadjusted separate models for girls ( $\mathrm{HR} 1.36,95 \% \mathrm{Cl} 1.05,1.78$ ) and boys (HR 1.47, 95\% Cl 1.15, 1,89). ${ }^{7}$ One study that, instead of $\mathrm{OHC}$ placements, assessed the risk for child protection registration among nearly 160000 children in West Sussex, found that the shorter the gestational age was the higher the risk of child protection registration was, even after adjustment for maternal age and socioeconomic position. ${ }^{6}$ The study also showed linear trends across birthweight z-score groups, indicating that rates of registrations increased by declining foetal growth. Comparability of study results between countries, however, can be affected by the differences in the organisation of child protection services.

\section{Conclusion}

This population-based study shows a dose-response relationship between the shorter length of gestation and out-of-home care $(\mathrm{OHC})$ placement risk: early preterm, late preterm and even early term children are at a higher risk in comparison to their full term born peers. The higher risk is explained by an increased number of $\mathrm{OHC}$ placements before the age of six. The study results further indicate that the association between gestational age and placement risk is only partly explained by shared common risk factors for both preterm birth and $\mathrm{OHC}$ placement, underlining the role of preterm birth as a potential risk factor for childhood adversity regardless of parental SEP or other early circumstances. This highlights the importance of directing professionals working with preterm children to increased sensitivity in noticing need of help and support. The consequences of preterm or early term births are not only medical but also social and affect both the child and the entire family. 


\section{Conflict of Interest}

The authors report no relevant potential conflicts of interest to disclose.

\section{Funding}

The study is supported by the Academy of Finland (Skidi-Kids program for 2010-2013 and grants 127437, 129306, 130326, 134791, 263924, 274794 and 315690 to Dr. Kajantie, and Clinical Researcher Grant 288966 to Dr. Hovi); European Commission (Horizon2020 award 733280 RECAP Research on Children and Adults Born Preterm to Dr Kajantie); the Doctoral Programs of public Health, University of Helsinki (to Dr. Alenius); the Finnish Foundation for Pediatric Research (to Drs. Kajantie and Hovi), the Signe and Ane Gyllenberg Foundation (to Drs. Alenius, Kajantie and Hovi); the Alli Paasikivi Foundation (to Dr. Hovi); the Sigrid Jusélius Foundation (to Dr. Kajantie); the Juho Vainio Foundation (to Drs. Kajantie and Alenius); the Novo Nordisk Foundation (to Dr. Kajantie); the Finnish Foundation for Cardiovascular Research (to Drs. Kajantie and Hovi); the Emil Aaltonen Foundation (to Dr. Kajantie and Dr. Hovi); the Paulo Foundation (to Dr. Alenius); and the Finnish Medical Foundation (to Dr. Alenius). The study funders had no role in the study design and conduct of the study; the collection, management, analysis, and interpretation of the data; the preparation, review, or approval of the manuscript; or the decision to submit the manuscript for publication.

\section{ACKNOWLEDGEMENTS}

The authors thank perinatologist Anneli Pouta (PEDEGO Research Unit, MRC Oulu, Oulu University Hospital and University of Oulu, Oulu, Finland; Faculty of Medicine; and Finnish Institute for Health and Welfare, Helsinki, Finland), for her valuable contribution, including participation in the administrative process, at the initial stage of the project. The authors also thank psychologist 
Marius Lahti-Pulkkinen (Department of Psychology and Logopedics, University of Helsinki, Helsinki, Finland; University BHF Centre for Cardiovascular Sciences, Queen's Medical Research Institute, University of Edinburgh, Edinburgh, UK; and Finnish Institute for Health and Welfare, Helsinki, Finland) and psychologist Sara Sammallahti (Department of Psychology and Logopedics, University of Helsinki, Helsinki, Finland; Children's Hospital, Helsinki University Hospital and University of Helsinki, Helsinki, Finland; Finnish Institute for Health and Welfare, Helsinki, Finland) for their significant assistance while preparing the covariates that reflect any maternal in-hospital treated psychiatric disorders. 


\section{REFERENCES}

1. Chawanpaiboon S, Vogel JP, Moller A-B, Lumbiganon P, Petzold M, Hogan D, et al. Global, regional, and national estimates of levels of preterm birth in 2014: a systematic review and modelling analysis. Lancet Global Health 2019;7:e37-46.

2. Alenius $S$, Kajantie $E$, Sund R, Näsänen-Gilmore $P$, Vääräsmäki $M$, Gissler $M$, et al. The missing siblings of infants born preterm. Pediatrics 2018;141(1):e20171354 .

3. Saigal S, Burrows E, Stoskopf BL, Rosenbaum PL, Streiner D. Impact of extreme prematurity on families of adolescent children. Journal of Pediatrics 2000;137(5):701-706.

4. Cronin CM, Shapiro CR, Casiro OG, Cheang MS. The impact of very low-birth-weight infants on the family are long lasting. A matched control study. Archives of Pediatrics and Adolescent Medicine 1995;149(2):151-158.

5. Singer LT, Davillier M, Bruening P, Hawkins S, Yamashita TS. Social support, psychological distress, and parenting strains in mothers of very low birth weight infants. Family Relations 1996;45:343-350.

6. Spencer N, Wallace A, Sundrum R, Bacchus C, Logan S. Child abuse registration, fetal growth, and preterm birth: a population based study. Journal of Epidemiology and Community Health 2006;60:337-340.

7. Kestilä L, Paananen R, Väisänen A, Muuri A, Merikukka M, Heino T et al. Risk factors for outof-home care. A longitudinal register based study on children born in Finland in 1987. [English summary]. Yhteiskuntapolitiikka 2012;1:34-52. http://urn.fi/URN:NBN:fi-fe201209117910 (accessed 30 Jan 2019).

8. Maclean MJ, Sims S, Bower C, Leonard H, Stanley FJ, O'Donnell M. Maltreatment risk among children with disabilities. Pediatrics 2017;139(4):(Suppl 1):P4.

9. Kalland M, Sinkkonen J, Gissler M, Meriläinen J, Siimes MA. Maternal smoking behavior, background and neonatal health in Finnish children subsequently placed in foster care. Child Abuse \& Neglect 2006;30:1037-1047.

10. Murphy JF, Jenkins J, Newcombe RG, Sibert JR. Objective birth data and the prediction of child abuse. Archives of Disease in Childhood 1981;56:295-297.

11. Benedict MI, White RB. Selected perinatal factors and child abuse. American Journal of Public Health 1985;75:780-781.

12. Sidebotham P, Heron J, The ALSPAC Study Team. Child maltreatment in the "children of the nineties:" the role of the child. Child Abuse \& Neglect 2003;27:337-352.

13. Shearman JK, Evans CE, Boyle MH, Cuddy L, Norman GR. Maternal and infant characteristics in abuse: a case control study. The Journal of Family Practice 1983;16(2): 289-293. 
14. Leventhal JM. Risk factors for child abuse: methodologic standards in case-control studies. Pediatrics. 1981;68(5):684-690.

15. Sankilampi U, Hannila M-L, Saari A, Gissler M, Dunkel L. New population-based references for birth weight, length and head circumference in singletons and twins from 23 to 43 gestation weeks. Annals of Medicine 2013;45(5-6):446-454 .

16. Armitage P, Berry G, Matthews JNS. Survival Analysis. In: Statistical Methods in Medical Research. 4th ed. Hoboken, NJ: Blackwell Science Ltd; 2002; pp. 568-590.

17. Rosenbaum PR, Rubin DB. The central role of the propensity score in observational studies for causal effects. Biometrika. 1983;70:41-55.

18. D'Agostino RB. Propensity score methods for bias reduction in the comparison of the treatment to a non-randomized control group. Statistics in Medicine 1998;17:2265-2281.

19. Statistics Finland. Statistical databases. Available at: http://stat.fi/tup/tilastotietokannat/index_en.htm [Accessed 14 August 2018, updated 30 July 2018].

20. Sipola-Leppänen $M$, Vääräsmäki $M$, Tikanmäki $M$, Hovi $P$, Miettola $S$, Ruokonen $A$, et al. Cardiovascular risk factors in adolescents born preterm. Pediatrics 2014;134;e1072.

21. Yang H, Kramer MS, Platt RW, Blondel B, Bréart G, Morin I, et al. How does early ultrasound scan estimation of gestational age lead to higher rates of preterm birth? American Journal of Obstetrics and Gynecology 2002;186(3):433-437.

22. Ejrnaes M, Ejrnaes M, Fredriksen S. Risk factors of entry in out-of-home care: an empirical study of Birth cohorts. Child Indicator Research 2011;4:21-44.

23. Franzén $E$, Vinnerljung $B$, Hjern A. The epidemiology of out-of-home care for children and youth: a national cohort study. British Journal of Social Work 2008;38:1043-1059.

24. Korja R, Latva R, Lehtonen L. The effects of preterm birth on mother-infant interaction and attachment during the infants first two years. Acta Obstetrica et Gynecologica Scandinavica 2012;91:164-173. 
Table 1. The characteristics of the first Index children of each mother within the cohort $(n=193033)$; and characteristics of the mothers $(n=193012)$ and registered fathers ( $n=190246$ ) according to gestational age category of the index child.

\begin{tabular}{|c|c|c|c|c|c|c|}
\hline & $\begin{array}{l}\text { Early Preterm } \\
23-33 \text { weeks }\end{array}$ & $\begin{array}{l}\text { Late Preterm } \\
34-36 \text { weeks }\end{array}$ & $\begin{array}{c}\text { Early Term } \\
37-38 \text { weeks }\end{array}$ & $\begin{array}{c}\text { Full Term } \\
39-41 \text { weeks }\end{array}$ & $\begin{array}{l}\text { Post Term } \\
42 \text { weeks }\end{array}$ & $\begin{array}{l}\text { Total Cohort } \\
23-42 \text { weeks }\end{array}$ \\
\hline Index children, $\mathrm{n}$ & 1966 & 6360 & 32989 & 143496 & 8222 & 193033 \\
\hline Length of gestation; weeks, mean (SD) & $30.7(2.8)$ & $35.9(0.8)$ & $38.2(0.5)$ & $40.3(0.8)$ & $42.2(0.2)$ & $39.8(1.7)$ \\
\hline Male, $\mathrm{n}(\%)$ & $1136(57.8)$ & $3487(54.8)$ & $17453(52.9)$ & $72697(50.7)$ & $4240(51.6)$ & $99013(51.3)$ \\
\hline Birthweight; g, mean (SD) & $1553(557)$ & $2730(419)$ & 3332 (474) & 3671 (459) & $3849(465)$ & 3568 (549) \\
\hline Birthweight SD score, mean (SD) & $-0.31(1.59)$ & $-0.22(1.36)$ & $-0.01(1.17)$ & $0.02(1.02)$ & $-0.03(1.01)$ & $0.00(1.07)$ \\
\hline Small for gestational age; SGA, n (\%) & 309 (15.7) & $633(10.0)$ & $1350(4.1)$ & $2950(2.1)$ & $200(2.4)$ & $5442(2.8)$ \\
\hline Severe infant morbidity, $\mathrm{n}(\%)^{\mathrm{a}}$ & $316(18.4)$ & $181(2.8)$ & $289(0.9)$ & $1087(0.8)$ & $84(1.0)$ & $2002(1.0)$ \\
\hline Developmental disorder or/and Intellectual disability, n (\%) & $52(2.6)$ & $51(0.8)$ & $198(0.6)$ & $726(0.5)$ & $56(0.7)$ & $1083(0.6)$ \\
\hline Cerebral palsy (CP), n (\%) & $172(8.7)$ & $43(0.7)$ & $85(0.3)$ & $257(0.2)$ & $19(0.2)$ & $576(0.3)$ \\
\hline Died during follow-up, $\mathrm{n}(\%)$ & $362(18.4)$ & $134(2.1)$ & $268(0.8)$ & $782(0.5)$ & $43(0.5)$ & $1589(0.8)$ \\
\hline One or more major anomalies, n (\%) & $111(5.6)$ & $194(3.1)$ & $549(1.7)$ & $1477(1.0)$ & $92(1.1)$ & $2423(1.3)$ \\
\hline Urban location of birth, $\mathrm{n}(\%)$ & $1131(57.5)$ & $3535(55.6)$ & $18152(55.0)$ & $79527(55.4)$ & $4826(58.7)$ & $107171(55.5)$ \\
\hline Placed into $\mathrm{OHC}$ before the end of follow-up, $\mathrm{n}(\%)$ & $107(5.4)$ & $304(4.8)$ & $1241(3.8)$ & $4582(3.2)$ & $328(4.0)$ & $6562(3.4)$ \\
\hline Age at first OHC placement; years, mean (SD) & $7.8(5.6)$ & $9.2(5.7)$ & $9.9(5.5)$ & $10.9(5.3)$ & $10.5(5.2)$ & $10.5(5.4)$ \\
\hline Information on fatherhood not registered to CPR, n (\%) & $141(7.2)$ & $179(2.8)$ & $508(1.5)$ & $1823(1.3)$ & $136(1.7)$ & $2787(1.4)$ \\
\hline One parent died before the end of follow-up, $n(\%)$ & $127(6.5)$ & $399(6.3)$ & $1740(5.3)$ & $6759(4.7)$ & $367(4.5)$ & $9392(4.9)$ \\
\hline Both parents died before the end of follow-up, $n(\%)$ & $8(0.4)$ & $6(0.1)$ & $56(0.2)$ & $143(0.1)$ & $10(0.1)$ & $223(0.1)$ \\
\hline Emigrated before the end of follow-up, n (\%) & $7(0.4)$ & $31(0.5)$ & $174(0.5)$ & $751(0.5)$ & $46(0.6)$ & $1009(0.5)$ \\
\hline Mothers, $\mathrm{n}$ & 1965 & 6359 & 32987 & 143481 & 8220 & 193012 \\
\hline Age at the birth of the index child; years, mean (SD) & $29.2(6.0)$ & $28.8(5.8)$ & $28.9(5.5)$ & $28.4(5.2)$ & $27.8(5.0)$ & $28.5(5.3)$ \\
\hline$<20, \mathrm{n}(\%)$ & $91(4.6)$ & $283(4.5)$ & $1142(3.5)$ & $4468(3.1)$ & $327(4.0)$ & $6311(3.3)$ \\
\hline $20-34, \mathrm{n}(\%)$ & $1475(75.1)$ & $4946(77.8)$ & $26375(80.0)$ & 120431 (83.9) & $7081(86.1)$ & $160308(83.1)$ \\
\hline$\geq 35, \mathrm{n}(\%)$ & $399(20.3)$ & $1130(17.8)$ & $5470(16.6)$ & $18582(13.0)$ & $812(9.9)$ & $26393(13.7)$ \\
\hline Age at the 1st OHC placement; years, mean (SD) & $34.5(8.2)$ & $36.6(8.6)$ & $36.7(8.4)$ & $37.3(7.8)$ & $36.6(7.7)$ & $37.1(7.9)$ \\
\hline Unmarried, $\mathrm{n}(\%)^{\mathrm{b}}$ & $579(29.5)$ & $1699(26.7)$ & $7266(22.0)$ & $31728(22.1)$ & $2199(26.8)$ & $43471(22.5)$ \\
\hline Smoked during pregnancy, $\mathrm{n}(\%)$ & $403(21.4)$ & $1190(19.1)$ & $5358(16.6)$ & $21579(15.3)$ & $1389(17.2)$ & $29919(15.8)$ \\
\hline
\end{tabular}


Pregnancy disorder, $\mathrm{n}(\%)^{\mathrm{c}}$

Late onset of antenatal care, $n(\%)^{d}$

Mode of delivery, $\mathrm{n}(\%)$

Two or more previous children, $\mathrm{n}(\%)^{\mathrm{e}}$

Previous interbirth interval $<18$ months, $\mathrm{n}(\%)$

Subsequent interbirth interval $<18$ months, $\mathrm{n}(\%)$

History of alcohol and/or substance misuse, $n(\%)^{f}$

History of any psychiatric disorder, $\mathrm{n}(\%)^{\mathrm{g}}$

Any psychiatric disorder prior to the $18^{\text {th }}$ birthday of the index child, $\mathrm{n}(\%)^{\mathrm{h}}$

Died before the $1^{\text {st }} \mathrm{OHC}$ placement of the index child, $\mathrm{n}(\%)$

Died during follow-up, $\mathrm{n}$ (\%)

Socioeconomic position; SEP, $\mathrm{n}(\%)$

Higher official

Lower official

Manual worker

Other ${ }^{i}$

Fathers, $n$

Age at the birth of the index child; years, mean (SD)

$$
\begin{array}{r}
<20 \text { years, } \mathrm{n}(\%) \\
20-34, \mathrm{n}(\%) \\
\geq 35, \mathrm{n}(\%)
\end{array}
$$

Age at the 1st OHC placement of the child; years, mean (SD)

Died before the 1st OHC placement of the index child, $\mathrm{n}(\%)$

Died during follow-up, $\mathrm{n}$ (\%)

Socioeconomic position; SEP, $\mathrm{n}(\%)$

$\begin{array}{cccccc}514(26.2) & 1407(22.1) & 5648(17.1) & 11890(8.3) & 407(5.0) & 19866(10.3) \\ 44(2.3) & 181(2.9) & 562(1.7) & 1626(1.1) & 124(1.5) & 2537(1.3) \\ & & & & & \\ 959(48.8) & 4509(70.9) & 25534(77.4) & 119643(83.4) & 6281(76.4) & 156926(81.3) \\ 12(0.6) & 150(2.4) & 945(2.9) & 6497(4.5) & 531(6.5) & 8135(4.2) \\ 994(50.6) & 1700(26.7) & 6508(19.7) & 17340(12.1) & 1408(17.1) & 27950(14.5) \\ 431(21.9) & 1398(22.0) & 8409(25.5) & 32788(22.9) & 1341(16.3) & 44367(23.0) \\ 67(7.2) & 155(5.3) & 715(4.0) & 2987(3.9) & 122(3.7) & 4046(4.0) \\ 194(19.2) & 477(13.7) & 2050(11.4) & 8950(10.8) & 590(11.1) & 12261(11.1) \\ 45(2.3) & 96(1.5) & 448(1.4) & 1504(1.0) & 93(1.1) & 2186(1.1) \\ 74(3.8) & 182(2.9) & 823(2.5) & 2709(1.9) & 162(2.0) & 3950(2.0) \\ 189(9.6) & 505(7.9) & 2212(6.7) & 8186(5.7) & 497(6.0) & 11587(6.0) \\ 5(4.7) & 9(3.0) & 41(3.3) & 108(2.4) & 5(1.5) & 168(2.6) \\ 59(3.0) & 138(2.2) & 498(1.5) & 1748(1.2) & 88(1.1) & 2531(1.3) \\ & & & & & \\ 265(13.6) & 987(15.6) & 5391(16.4) & 23438(16.4) & 1261(15.4) & 31342(16.3) \\ 703(36.1) & 2388(37.8) & 12707(38.7) & 56372(39.1) & 3202(39.1) & 75372(39.2) \\ 514(26.4) & 1490(23.6) & 7633(23.2) & 32480(22.7) & 1940(23.7) & 44057(22.9) \\ 468(24.0) & 1446(22.9) & 7101(21.6) & 30500(21.4) & 1776(21.7) & 41291(21.5) \\ 1825 & 6181 & 32481 & 141673 & 8086 & 190246 \\ 32.0(6.6) & 31.6(6.3) & 31.7(6.1) & 31.3(5.7) & 30.8(5.7) & 31.4(5.8) \\ 29(1.6) & 75(1.2) & 267(0.8) & 1059(0.7) & 71(0.9) & 1501(0.8) \\ 1261(69.1) & 4402(71.2) & 23398(72.0) & 106821(75.4) & 6252(77.3) & 132134(74.7) \\ 535(29.3) & 1704(27.6) & 8816(27.1) & 33793(23.9) & 1763(21.8) & 46611(24.5) \\ 38.6(9.9) & 39.7(9.1) & 40.2(8.7) & 41.0(8.5) & 40.3(9.2) & 40.7(8.6) \\ 3(3.2) & 20(7.1) & 65(5.6) & 264(6.1) & 13(4.2) & 365(5.9) \\ 76(4.2) & 267(4.3) & 1298(4.0) & 5154(3.6) & 289(3.6) & 7084(3.7) \\ 341(18.8) & 1176(19.2) & 6729(20.9) & 29079(20.7) & 1627(20.3) & 38952(20.6) \\ 306(16.9) & 1054(17.2) & 5803(18.0) & 25569(18.2) & 1418(17.7) & 34150(18.1)\end{array}$


SD - Standard deviation; OHC - out-of-home care; CPR - Central Population Register

a Severe infant morbidity includes neonatal diagnoses: seizure, intraventricular haemorrhage (IVH), cerebral infarction, periventricular leukomalacia, birth trauma, hypoxic ischemic encephalopathy (HIE), necrotizing enterocolitis (NEC), septicaemia, pneumonia, primary atelectasis, patent ductus arteriosus (PDA), infant respiratory distress syndrome (IRDS) and respiratory failure of the newborn. Composition of this covariate is presented in detail elsewhere. ${ }^{2}$

${ }^{b}$ Maternal marital status at the birth of the index child.

c Pregnancy disorder includes gestational diabetes, gestational hypertensive disorder, and intrahepatic cholestasis of pregnancy. A complete list of diagnoses included in this covariate is available in Supplementary Methods.

d 1 st appointment to the antenatal clinic after 22 completed weeks of gestation.

e Biological or adoptive.

${ }^{f}$ Maternal in-hospital treatment(s) for alcohol and/or substance abuse at the birth or prior to the birth of the index child. Composition of this covariate is presented in detail in eTable 1.

g Maternal in-hospital treatment(s) for any psychiatric disorder at the birth or prior to the birth of the index child. A complete list of diagnoses included in this covariate is available in Supplementary Methods.

${ }^{h}$ Maternal in-hospital treatment(s) for any psychiatric disorder from the establishment of The Care Register for Health Care (1967) to the end of follow-up. A complete list of diagnoses included in this covariate is available in Supplementary Methods.

' Other includes entrepreneurs, farmers, students, pensioners, unemployed, housewives and mothers or fathers with unclassifiable or unknown SEP.

The amount of missing data were $0.5 \%$ for maternal marital status, $2.0 \%$ for maternal smoking in pregnancy, $0.8 \%$ for the onset of antenatal care, $0.0 \%$ ( $n=1$ ) for the mode of delivery, and $1.0 \%$ for maternal SEP. For paternal SEP the amount of missing data was $1.2 \%$. Data on other variables presented in this table are complete. Note that $47.0 \%$ of mothers did not have previous child, and $42.6 \%$ of mothers did not have a subsequent one. 


\section{FIGURE LEGENDS}

Figure 1. Flow-chart.

Figure 2. The number of first out-of-home care $(\mathrm{OHC})$ entries by the age (years) of the index child within different gestational age categories. The Figure covers only the first index child of each mother within the cohort (a total of 6562 first entries, of which 328 were those of born post term).

Figure 3. Hazard ratios (HR; 95\% confidence intervals) for $\mathrm{OHC}$ placement by the gestational age category of the first index child of each mother (gestational age 39-41 completed weeks is the reference $[H R=1.0])$.

Figure 3. [Footnotes]:

A. Follow-up period from 0 to 18 years of age. Model 0 is the unadjusted model. Model 0 s is stratified by the maternal socioeconomic position at the birth of the index child, and the birth year of the index child. Model 6 is stratified as Model Os and adjusted for the maternal age and marital status at the birth of the index child, maternal smoking in pregnancy, late onset of antenatal care, the number of previous maternal live-born children, previous maternal interbirth interval, urban residence of the mother at the birth of the index child, time-dependent covariate for the onset of the first maternal psychiatric in-hospital treatment period, smallness for gestational age status, developmental disorder or intellectual disability, cerebral palsy, major anomaly, the sex of the index child, the paternal socioeconomic position and age at the birth of the index child. Models from 1 to 5 are available in eTable 4.

B. Follow-up periods of $0-5$ years; $6-12$ years; $13-17$ years. Fully adjusted hazard ratios ( $95 \%$ confidence intervals) for $\mathrm{OHC}$ placement within certain age categories. Analyses are stratified and adjusted as in Model 6 at Figure 3A. Model 0s is presented in eTable 6. 
236186 live born children in Finland between Jan 1987 and Sep 1990

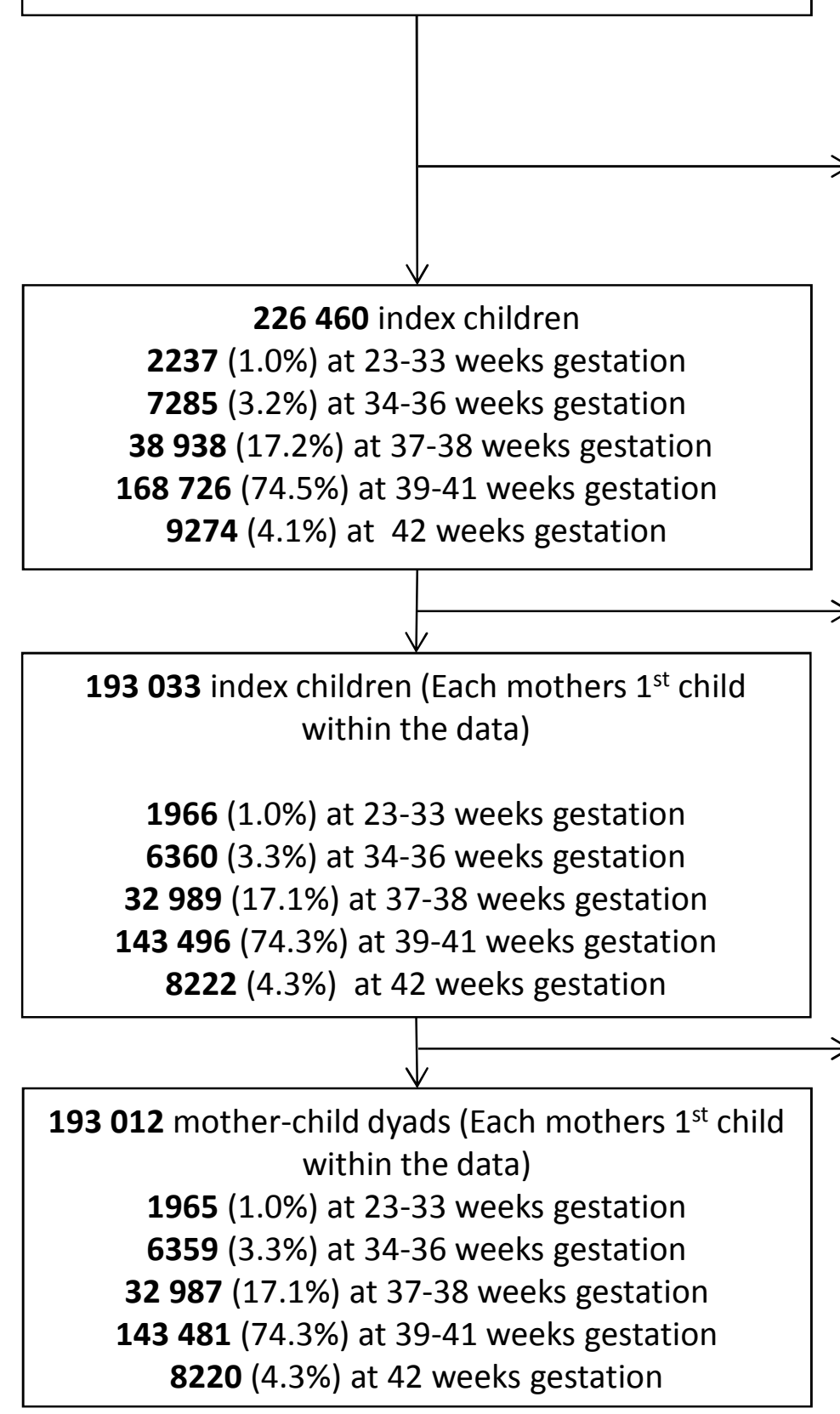

564 (0.5\%) children with missing or incorrect personal identification number

$70(0.03 \%)$ children without data from CPR

5244 (2.2\%) children from multiple births

2945 (1.3\%) without information on gestational age

$432(0.2 \%)$ gestational age $<23$ weeks or $>=43$ weeks

471 (0.2\%) with missing or incorrect birthweight SD-score

33427 mothers with $2^{\text {nd }}$ or higher order children

$271(0.8 \%)$ at 23-33 weeks gestation

$925(2.8 \%)$ at $34-36$ weeks gestation $5949(17.8 \%)$ at $37-38$ weeks gestation 25230 (75.5\%) at 39-41 weeks gestation 1052 (3.1\%) at GA 42 weeks gestation

$21(0.0 \%)$ mothers without data in CPR $1(0.0 \%)$ at $23-33$ weeks gestation $1(0.0 \%)$ at $34-36$ weeks gestation $2(0.0 \%)$ at $37-38$ weeks gestation $15(0.0 \%)$ at $39-41$ weeks gestation $2(0.0 \%)$ at 42 weeks gestation 

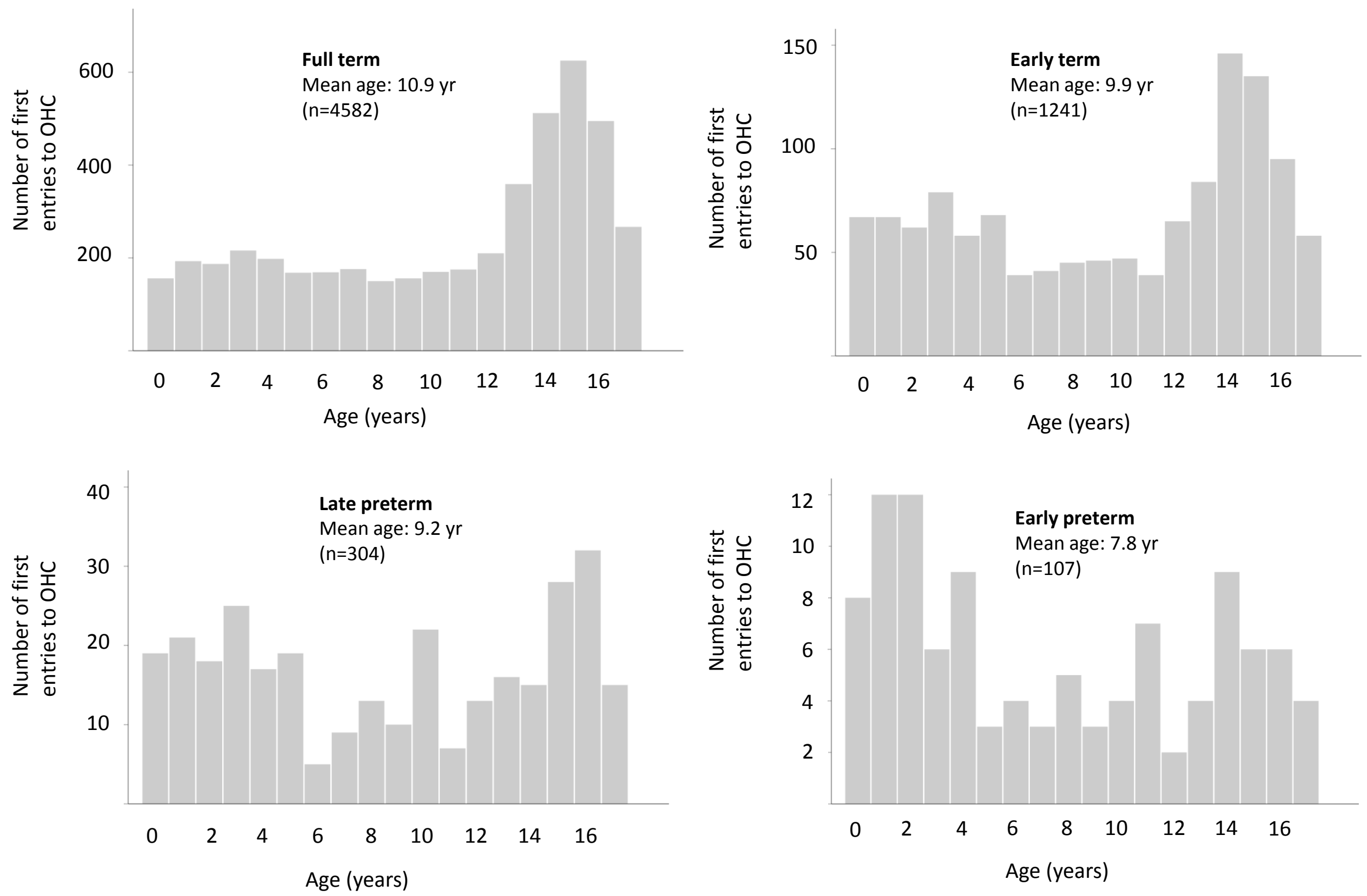

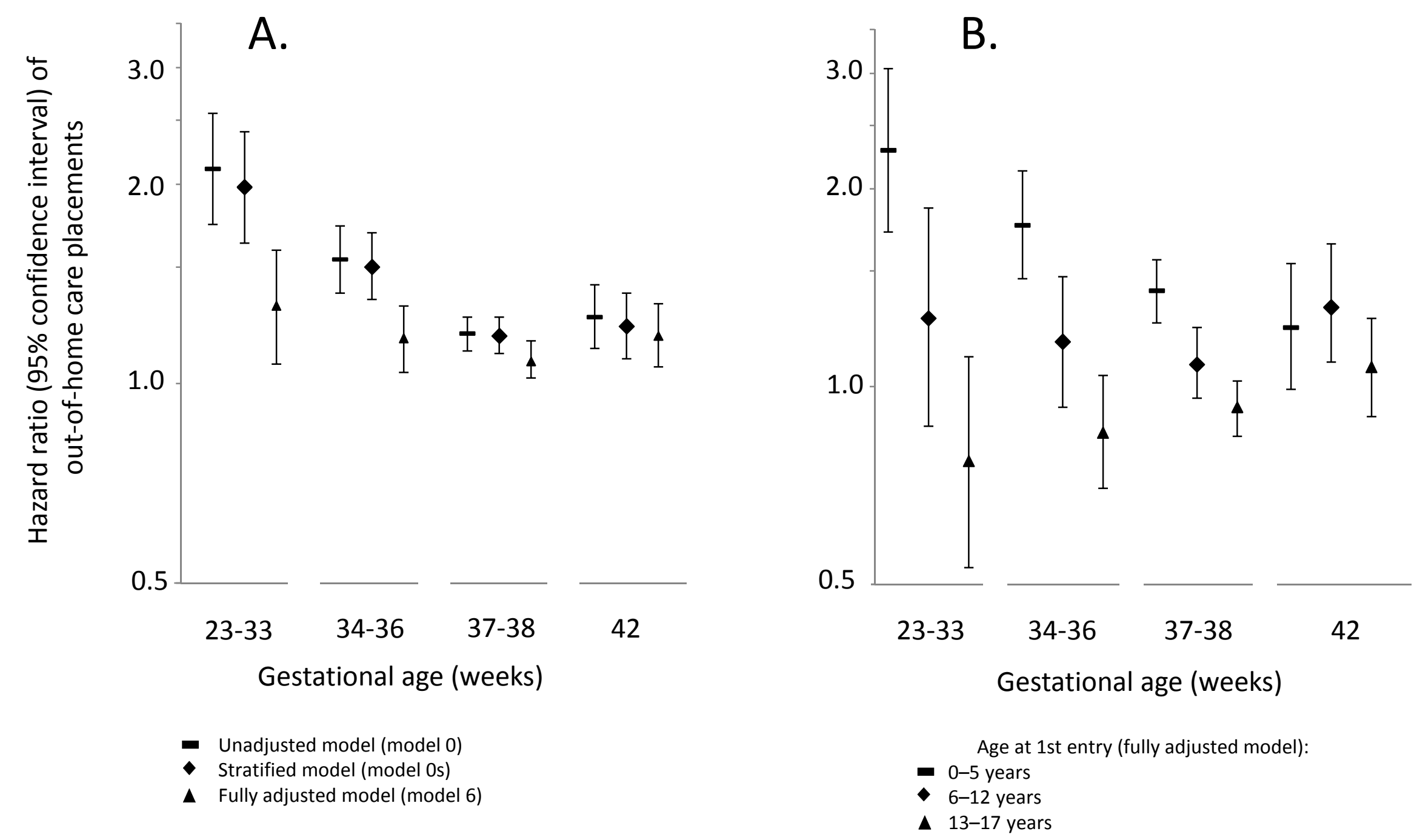


\section{Out-of-Home Care Placements of Children and Adolescents Born Preterm: A Register-Based Cohort Study}

Alenius et al. 2019

\section{Supplementary Material}

\section{SUPPLEMENTARY METHODS}

\section{Description of the registers}

The Child Welfare Register (CWR) provides complete data on children's out-of-home care (OHC) entries, durations and placement settings since January 1, 1991. It also encompasses retroactive data for those children who were recorded to CWR both before and after its actual establishment in 1991. Hence, CWR lacks data on such children who were returned home from OHC placement prior to the establishment of the CWR, and who were never again placed into $\mathrm{OHC}$ after that time point. The Finnish Institute for Health and Welfare THL (STAKES until December 31, 2008) compiles and processes the CWR data. The data are regarded to be reliable. The comparability of the data during the follow-up period (until September 30,2008) is good, as no changes appear in the concepts and definitions until 2007, when reporting of the type of care settings, primarily, was slightly modified. ${ }^{1}$ The CWR does not provide data on the causes of OHC placements because of the difficulties associated with the categorisation and collection of such data nor does it provide information on any involvement of child protection authorities beyond OHC placements. In 1987, according to the National Research and Developmental Centre for Welfare and Health (STAKES) survey $^{2}$ the main reason for the placement of a child into the family- or institutional care were harmful environmental factors $(86.0 \%)$ such as alcohol and substance abuse of the parents, neglect of care and parental mental problems. The developmental and behavioural factors of the child were the reason for placement in $8.9 \%$ of cases and social problems in $5.1 \%$ of cases. The information on whether the distributions of the reasons for placement to family- or institutional care differ between preterm born children and the general population is not available in these statistics.

In addition to the CWR data on those born between 1987 and 1990, we were able to access additional complete aggregated data from the CWR for years 1991 to 2008, which allowed us to estimate the proportion of children who enter OHC in the first four years of life but who do not return into the $\mathrm{OHC}$ placement during subsequent years, and were therefore missed in our setting. The percentage of missed $\mathrm{OHC}$ placements for children placed into $\mathrm{OHC}$ prior to six months of age was $12.0 \%$. Corresponding percentages for children who were one, two, or three years of age at first 
entry to $\mathrm{OHC}$ were: $11.6 \%, 6.2 \%$, and $4.1 \%$. This translates to a loss of approximately $86 \mathrm{OHC}$ placements due to the time gap between the births within the cohort and the establishment of the CWR.

The Registers at Statistics Finland encompass population-wide individual-level data on education, employment and socioeconomic position (SEP) of all citizens in Finland. The classification of SEP within this study is based on the Statistics Finland's classification standard of socioeconomic groups from 1983 and 1989. ${ }^{3,4}$ These classifications take into account a person's occupation, occupational status, the nature or type of the work and main activity (such as being a family member, student, pensioner, unemployed or a part of the labour force).

\section{Cohort members}

Live born children with valid personal identity code in Finland between January 1, 1987 and September 30, 1990, identified from MBR, formed the initial study population. This time period was chosen because the MBR is available from January 1, 1987 onwards, and substantial changes occurred in the MBR on October 1, 1990, and would have affected the uniformity of the data in use.

\section{Additional information on covariates included in the models}

We did not adjust for maternal or paternal SEP after the birth of the index child in order to avoid reverse causality. Instead, we used maternal and paternal socioeconomic positions at the time of the birth of the index child, and categorised them in four subgroups: SEP Group I included upper officials, SEP group II included lower officials, SEP Group III included manual workers, and the SEP Group IV, 'Others', included all other groups (such as students, pensioners, farmers, entrepreneurs, unemployed and parents with an unclassifiable or unknown SEP). For index children born before the July 1, 1988, we used information on parental SEP registered December 31, 1985, and for the rest of the index children, the SEP registered by December 31, 1990. Information on parental SEP between 1986 and 1989 was unavailable due to SEP data documentation that, at that time, occurred at an interval of five years only.

Maternal and paternal ages at the birth of the index child were categorised in three groups: less than 20 years, from 20 to 34 years, and 35 years or older. The MBR served as a source for maternal marital status (married or unmarried) at the birth of the child and for information on maternal smoking in pregnancy (yes/no). Data on smoking were recorded to the MBR as it was reported at the first antenatal clinic appointment, usually at 9 to 10 completed weeks of gestation. As MBR also encompasses the date of the first maternal visit to the antenatal clinic, we assessed this data by formulating a variable to reflect maternal in-time attendance to antenatal care (first appointment before the end of the $22^{\text {nd }}$ gestational week/ first appointment in $23^{\text {rd }}$ week of gestation or later). In Finland, pregnant women must visit a doctor or a maternity and child welfare clinic for a health check before the fifth month of pregnancy in order to be able to claim a maternity grant; namely a maternity package (including baby clothes, care products and other materials) or a tax-free monetary benefit. It is rare not to claim for that, and not to attend antenatal care in a timely fashion; only $1.3 \%$ of mothers within the cohort did not attend antenatal care before the end of their $22^{\text {nd }}$ week of gestation (Table 1, eTable 3). Data on maternal pregnancy disorders were derived from the MBR and the Finnish Care Register for Health Care (CRHC). A maternal pregnancy disorder was 
defined as present if any of the following three diagnoses appeared within the MBR or CRHC during the index pregnancy (from 20 weeks before the expected date of delivery of the index child to 90 days after the actual birth date): (1) gestational diabetes (International Classification of Diseases, Eighth Revision code 761.10, International Classification of Diseases, Ninth Revision codes 6480A and 6488A), (2) maternal hypertensive disorder (International Classification of Diseases, Eighth Revision codes 637.01 and 637.036-37.99 or (International Classification of Diseases, Ninth Revision codes 6420X-6429C) and (3) intrahepatic cholestasis of pregnancy (International Classification of Diseases, Eighth Revision codes 639.00-639.09 or (International Classification of Diseases, Ninth Revision codes 6467A and 6467X). Information on the number of maternal previous live born children (biological or adoptive) came from the CPR, and was categorized as none, one or two or more. Accordingly, as closely spaced pregnancies may reflect cumulative stressors, and the burden of daily caretaking of the children due to insufficient parental resources, we assessed the time interval between the births of the index child and the child's previous sibling, that is, the previous maternal interbirth interval (more than 18 months or no previous siblings/ 18 months or less)..$^{5}$ The dates of the births of the siblings of the index children were also available from the CPR. Information on maternal place of residence at the birth of the index child came from the MBR and was categorised as urban or nonurban.

Maternal psychiatric disorders ${ }^{6,7}$ and alcohol and drug abuse or addictions ${ }^{5,8,9}$ serve as strong risk factors for out-of-home care placement and child maltreatment; thus we in our main analyses adjusted for in-hospital treated psychiatric disorder in time-dependent manner (no first maternal inhospital psychiatric treatment periods during follow up/ maternal first in-hospital psychiatric treatment period within one year/ maternal first in-hospital psychiatric treatment period over one year ago). This cut-off point in the time-dependent variable was selected because the risk for OHCplacement appeared to be highest during the first year following the onset of the first maternal psychiatric treatment period (eFigure 1). Diagnoses included in this time-dependent covariate cover dementias, non-organic psychiatric disorders and alcohol intoxication if alcohol intoxication diagnosis was set as the main diagnosis (International Classification of Diseases, Tenth Revision (ICD-10): all codes in categories F00 to F03, F11 to F19, G30, the diagnosis F05.1, and corresponding diagnosis codes that follow International Classification of Diseases, Ninth Revision (ICD-9): all codes in categories 290 to 292, 295 to 309, 312 to 319 and codes 2941A, 3050A, $3310 \mathrm{~A}$ and 4378A, as well as corresponding diagnosis codes that follow International Classification of Diseases, Eighth Revision (ICD-8): all codes in categories 290 to 291, 295 to 301, 302.10 to 308, and codes 310 and 294.40). Any first maternal in-hospital treatment period was defined as having at least one of the above mentioned diagnoses for the first time within the Finnish Care Register for Health Care (CRHC) between the year 1969 (the start of ICD-8 classification) and the end of the follow-up period. All above mentioned diagnosis codes were included, regardless of the subspecialty of the in-hospital care period. The variable on maternal alcohol and substance abuse (eTable 1) was not included in the models as a separate covariate as $53.5 \%$ of those mothers who had any psychiatric disorder had also in-hospital treatment period resulting from alcohol and substance abuse.

As disabling conditions, such as developmental and intellectual disabilities of the child, may affect the propensity for out-of-home care placement(s), other child protection services, or for child 
maltreatment, ${ }^{10-12}$ we made an aggregate variable reflecting this condition. The variable comprises of (1) any developmental disorders (International Classification of Diseases, Tenth Revision: all diagnosis codes in category F84; and International Classification of Diseases, Ninth Revision: codes 2990, 2998 and 2999) and (2) any intellectual disabilities (International Classification of Diseases, Tenth Revision: all diagnosis codes in categories F70 to F79; and International Classification of Diseases, Ninth Revision: diagnosis codes in categories 317 to 319). A developmental and/or intellectual disability of the index child was defined to as having at least one of the diagnoses above documented within the Finnish Care Register for Health Care during the follow-up period.

Even though most of the parents cope well regardless of the added challenges of daily caretaking of a child with a disability we considered cerebral palsy (CP) as a such characteristic of a child that could serve as a risk factor for $\mathrm{OHC}$ placement. ${ }^{13}$ Therefore, we incorporated a variable reflecting this condition in our analyses. An index child was defined to have cerebral palsy if any of the diagnosis codes in category G80 (International Classification of Diseases, Tenth Revision) or in category 343 (International Classification of Diseases, Ninth Revision) appeared in the Finnish Care Register for Health Care during the follow-up period. Variables reflecting developmental and/or intellectual disabilities and cerebral palsy were included in the models as two separate covariates as $13.4 \%$ of index children with a developmental disorder and/or intellectual disability also had cerebral palsy.

The birth weight standard deviation scores were assessed by using current national growth charts. ${ }^{14}$ The index child's smallness for gestational age status (SGA) was defined as less than -2 SD as recommended in a consensus statement of the International Societies of Pediatric Endocrinology and Growth Hormone Research Society. ${ }^{15}$ Data on major congenital anomalies originated from RCM and was dichotomised (any major anomaly/ no major anomalies).

Information on parental dates of death came from PCR. As maternal deaths were more frequent among the mothers' of preterm born infants and serve as a rational risk factor for outcome, we tested the time-dependent effect of maternal death on the out-of-home care placement risk. After adding this time-dependent variable (mother alive/ mother died within one year/ mother died over one year ago) the estimates of different gestational age groups remained virtually unchanged. After adjusting for the time-dependent variable of paternal death (father alive/ father dead), the biggest difference in estimates was among the early preterm group, in which the HR attenuated from 1.98 $(95 \%$ CI $1.63,2.40)$ to $1.84(95 \%$ CI $1.50,2.26)$ (eTable 2). As parental deaths were rare during the follow-up period of our study (Table 1, eTable 3) and because we considered their effect as marginal on the outcome, we decided not to adjust for it. Justification for selected time cut-off points in time-dependent variables of maternal and parental deaths is presented in eFigure 2 ab.

\section{Propensity score matching}

In sensitivity analyses propensity score matching (PSM) was applied to match cases (gestational age 23 to 38 weeks, or 42 completed weeks of gestation) with controls (gestational age 39 to 41 completed weeks of gestation) who shared a similar value of propensity score. ${ }^{16}$ As the aim of propensity score matching was to investigate the effect of balanced covariate distributions among groups with different gestational ages, variables the propensity score was estimated with were the 
same as incorporated in Models ( 0 s to 6 ) in main and sensitivity analyses with one exception: a maternal in-hospital treated psychiatric disorder prior to the birth of the index child served as a covariate that was incorporated in matching algorithm instead of the time-dependent one described above. Diagnosis codes included in this conventional covariate of maternal psychiatric disorder prior to the birth of the index child were: all codes in categories 290 to 292, 295 to 309, 312 to 319 and codes 2941A, 3050A, 3310A and 4378A (International Classification of Diseases, Ninth Revision); and the corresponding diagnosis codes that follow International Classification of Diseases, Eighth Revision: all codes from categories 290 to 291, 295 to 301 and 310, as well as codes from 302.10 to 308 and code 294.40). Thus the propensity score was estimated with the following variables: (1) the maternal socioeconomic position (SEP) at the birth of the index child, (2) the birth year of the index child, (3) the maternal age at the birth of the index child, (4) the maternal marital status at the birth of the index child, (5) maternal smoking in pregnancy, (6) late onset of antenatal care, (7) the number of previous maternal live born children, (8) previous maternal interbirth interval, (9) the urban location of birth of the index child, (10) any maternal psychiatric disorder prior to the birth of the index child, (11) smallness for gestational age (SGA) status of the index child, (12) developmental disorder or intellectual disability of the child, (13) cerebral palsy, (14) major anomaly, (15) sex of the index child, (16) the paternal socioeconomic position, and (17) the paternal age at the birth of the index child. These covariates were chosen based on previous literature $6,8,17,18$ or on empirical knowledge. They were recoded as two to five category covariates, even if they were continuous in main analyses. The data were divided in five smaller data according to maternal SEP (including separate category for missing data), and a oneto-one nearest neighbour matching without replacement was utilised within each of these data with a maximum 0.01 difference in propensity scores eligible for use in matching. These data were then rejoined for analysis. A total of $178(0.3 \%)$ cases were excluded due to failure to satisfy a matching criterion. Standardised mean differences of the propensity scores and the covariates served as tools for the assessment of the balance between the matched groups.

\section{Assessment of unmeasured confounding}

E-value ${ }^{19}$ was employed as a tool to assess the effect of potential unmeasured confounding. It illustrates the magnitude of unmeasured confounding that is "needed" to negate the observed results. In the fully adjusted model in the main analyses the E-value for the early preterm group was 1.95 indicating that residual confounding could explain the observed association if there is an unmeasured covariate with a relative risk association at least of magnitude 1.95 with both preterm birth and out-of-home care placement prior to the age of 18 years. The E-values for late preterm and early term groups were 1.62 and 1.37. (The corresponding lower limits of the confidence intervals were 1.34, 1.27, and 1.21.) In light of the observed effects of the covariates in the models it is not inconceivable that such residual confounding exists that could annul the observed results at least among those born at 34 completed weeks of gestation or later.

\section{Assessment of missing data by exclusion of cases with incomplete data}


In main analyses we included index children with missing data in our analyses, by coding the missing values within dichotomous categorical covariates as 0 , and by coding the missing data on socioeconomic position (SEP) into category 'Other'. In sensitivity analysis we excluded cases with incomplete data. The results of this sensitivity analysis showed a minimal change on point estimates: the largest difference in fully adjusted estimates was among the early preterm group, where the HR attenuated from 1.31 (95\% CI 1.07, 1.59) to 1.28 (95\% CI 1.03, 1.59). The estimates of the late preterm group attenuated from HR 1.17 (95\% CI 1.04, 1.31) to HR 1.16 (95\% CI 1.03 , 1.32), and those of the early term group from HR 1.08 (95\% CI 1.02, 1.16) to HR 1.07 (95\% CI $1.00,1.16)$.

\section{Effect of Smallness for Gestational Age (SGA) on out-of-home care placement risk}

The effect of smallness for gestational age (SGA) status differed by gestational age category ( $P$ for interaction $<.001)$. For full term born children who were born small for gestational age the hazard ratio for out-of-home care placement was HR 2.82 (95\% CI 2.50, 3.18). The corresponding hazard ratios for early term, late preterm and early preterm groups were HR 2.81 (95\% CI 2.37, 3.34), HR 1.50 (95\% CI 1.10, 2.04) and HR 0.78 (95\% CI 0.45, 1.36). The effect of smallness for gestational age (SGA) status on placement risk declined with decreasing gestational age so that smallness for gestational age had no effect within the early preterm group.

\section{Effect of maternal socioeconomic position on out-of-home care placement risk}

The effect of maternal socioeconomic position at the birth of the index child on the placement risk of the child differed significantly in the five gestational categories ( $P$ for interaction .022 ) with a slight increase in late preterm group. The hazard ratios for early preterm, late preterm, early term and full term groups were HR 4.02 (95\% CI 2.59, 6.24), HR 4.71 (95\% CI 3.64, 6.10), HR 3.58 $(95 \%$ CI $3.19,4.01)$ and HR 3.34 (95\% CI 3.15, 3.54).

\section{SUPPLEMENTARY REFERENCES:}

1. National Institute for Health and Welfare [internet]. Finland. Information on Statistics. Quality descriptions: Child Welfare [updated 14 November 2018 ; assessed 26 January 2019]. Available at: https://thl.fi/en/web/thlfi-en/statistics/information-onstatistics/quality-descriptions/child-welfare.

2. Muuri A. Child Welfare 1987, 1991; National Research and Development Centre for Welfare and Health (STAKES). Helsinki, 1993.

3. Central Statistical Office of Finland. Classification of Socio-Economic Status. Classification of Occupational Status.1983. Helsinki. 1983(17). [Summary and 
classifications in English]. [assessed 2019 Jan 26]. Available at: http://www.doria.fi/handle/10024/98858.

4. Statistics Finland. Classification of Socio-economic Groups 1989. Helsinki. 1989(17). [accessed 26 January 2019]. Available at:

https://www.stat.fi/meta/luokitukset/sosioekon_asema/versio_en.html.

5. Thompson EL, Thompson LA, Black EW, Esernio-Jenssen D, Hardt N, Das R, et al. Identifying indicators during pregnancy for child maltreatment. Maternal and Child Health Journal 2013;17:1817-1824.

6. Kestilä L, Paananen R, Väisänen A, Muuri A, Merikukka M, Heino T et al. Risk factors for out-of-home care. A longitudinal register based study on children born in Finland in 1987. [English summary]. Yhteiskuntapolitiikka 2012;1:34-52. http://urn.fi/URN:NBN:fi-fe201209117910 (accessed 30 Jan 2019).

7. Park JM, Solomon P, Mandell DS. Involvement in the child welfare system among mothers with serious mental illness. Psychiaticr Services. 2006;57:493-497.

8. Franzén E, Vinnerljung B, Hjern A. The epidemiology of out-of-home care for children and youth: A national cohort study. British Journal of Social Work 2008;38:1043-1059.

9. Sarkola T, Kahila H, Gissler M, Halmesmäki E. Risk factors for out-of-home custody child care among families with alcohol and substance abuse problems. Acta Pcediatrica 2007;96:1571-1576.

10. Halfon N, Mendonca A, Bercowitz G. Health status of children in foster care - the experiments of the center for vulnerable child. Archives of Pediatrics Adolescent Medicine 1995;149:386-392.

11. Spencer N, Devereux E, Wallace A, Sundrum R, Shenoy M, Bacchus C, et al. Disabling conditions and registration for child abuse and neglect: a population-based study. Pediatrics 2005;116:609-613.

12. Hibbard RA, Desch LW, and the Committee on Child Abuse and Neglect and Council on Children with Disabilities. Maltreatment of children with disabilities. Pediatrics 2007;119:1018-1025.

13. Raina P, O’Donnell M, Rosenbaum P, Brehaut J, Walter SD, Russell D, et al. The health and well-being of caregivers of children with cerebral palsy. Pediatrics $2005 ; 115 \mathrm{e} 626$.

14. Sankilampi U, Hannila M-L, Saari A, Gissler M, Dunkel L. New population-based references for birth weight, length and head circumference in singletons and twins from 23 to 43 gestation weeks. Annals of Medicine 2013;45(5-6):446-454. 
15. Clayton PE, Cianfarani S, Czernichow P, Johansson G, Rapaport R, Rogol A. Management of the child born small for gestational age through adulthood: a consensus statement of the International Societies of Pediatric Endocrinology and Growth Hormone Research Society. The Journal of Clinical Endocrinology \& Metabolism 2007;92:804-810.

16. Rosenbaum PR, Rubin DB. The central role of the propensity score in observational studies for causal effects. Biometrika. 1983;70:41-55.

17. Goldenberg RL, Cullhane JF, Iams JD, Romero R. Epidemiology and causes of preterm birth. Lancet. 2008;371:75-84.

18. Bebbington A, Miles J. The background of children who enter local authority care. British Journal of Social Work. 1989;19:349-368.

19. VanderWeele TJ, Ding P. Sensitivity analysis in observational research: introducing the E-value. Annals of Internal Medicine. 2017;167:268-274.

20. Alenius S, Kajantie E, Sund R, Näsänen-Gilmore P, Vääräsmäki M, Gissler M, et al. The missing siblings of infants born preterm. Pediatrics 2018;141(1):e20171354. 


\section{SUPPLEMENTARY FIGURES:}




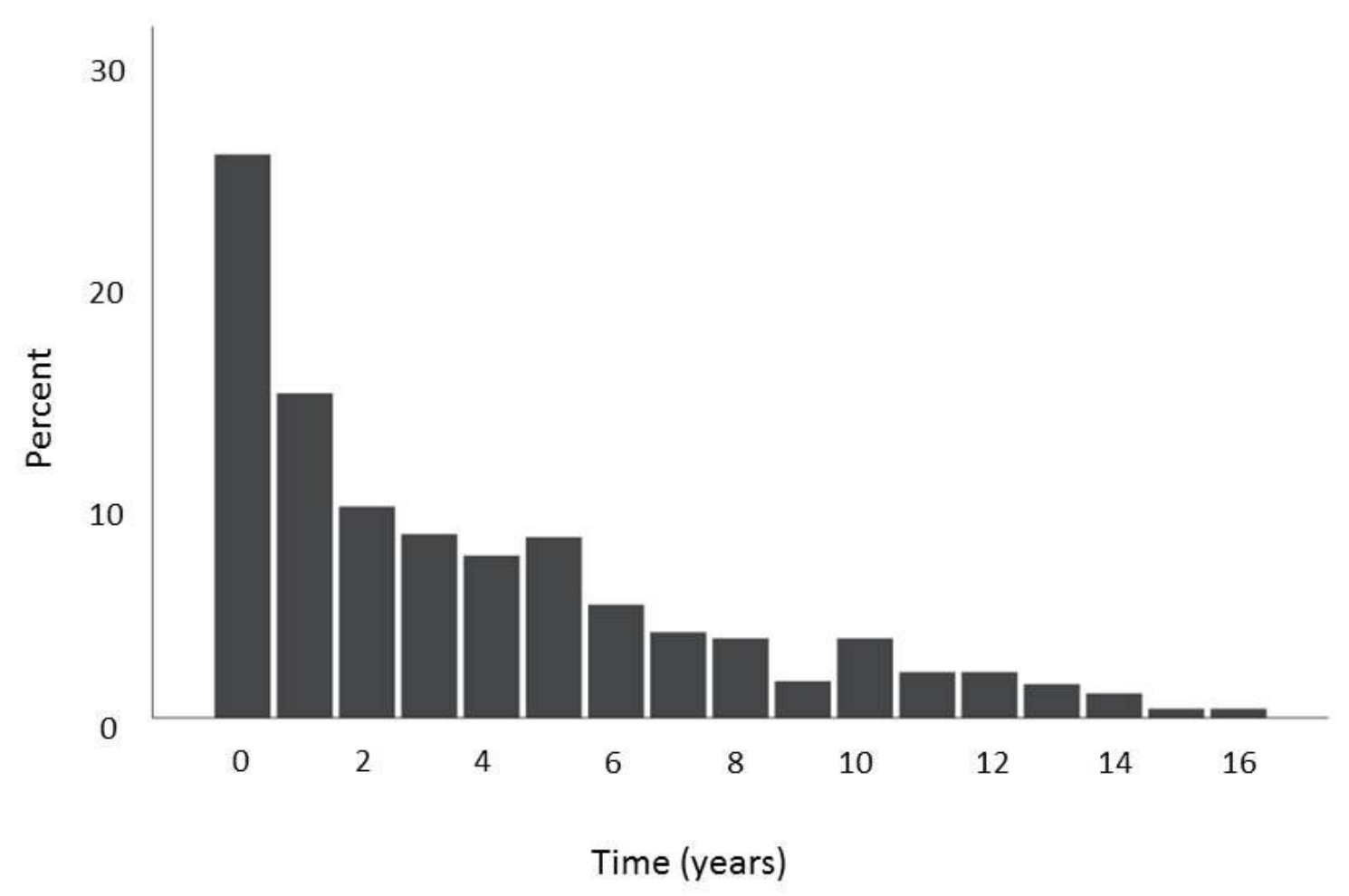

eFigure 1. The time (years) elapsed from the onset of the first maternal psychiatric in-hospital treatment period after the birth of the index child to the index child's first out-of-home care (OHC) entry. Figure covers only the first child of each mother within the cohort. 

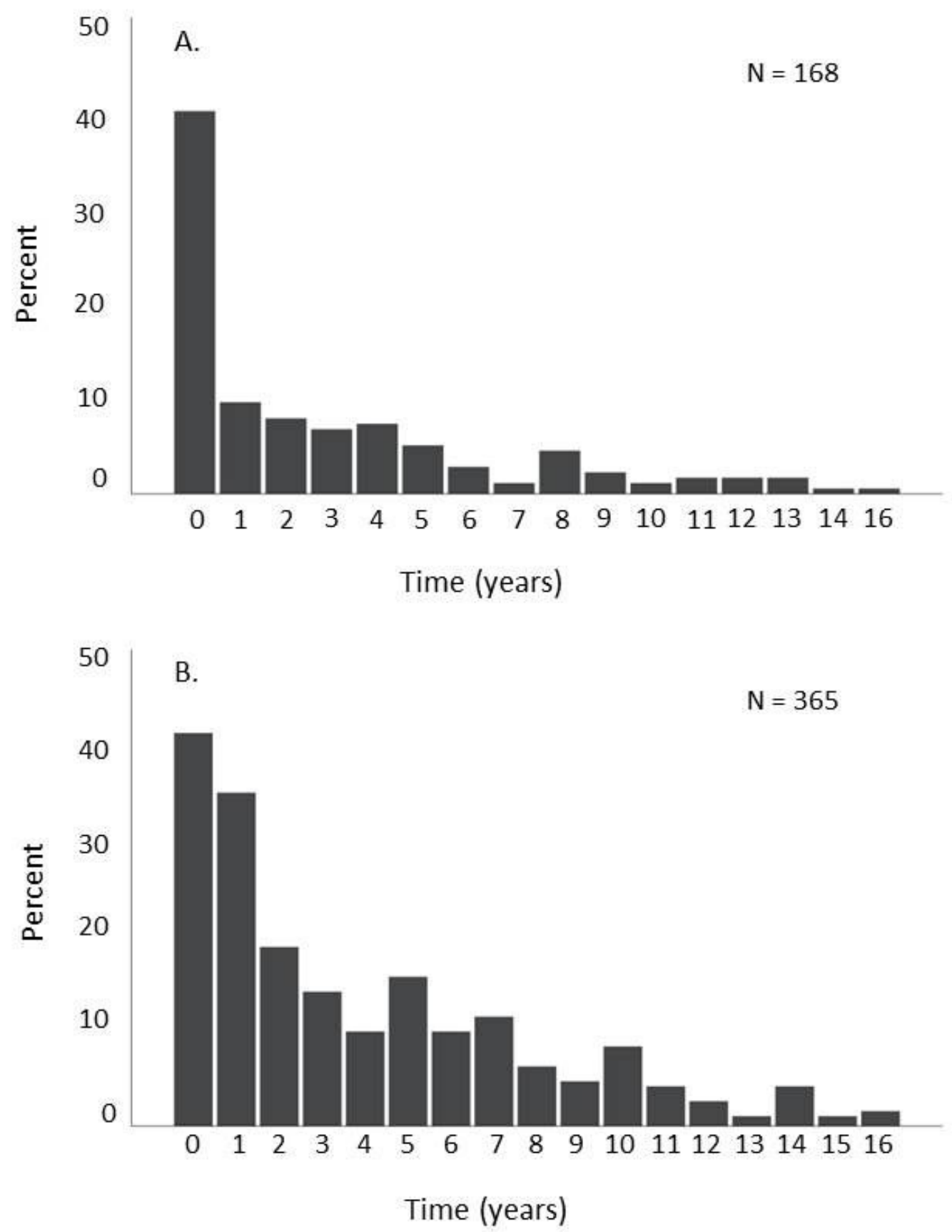

eFigure 2ab. Time (complete years) from maternal (A.) or paternal (B.) death to the onset of the first out-of-home care $(\mathrm{OHC})$ placement of the index child within all gestational age categories combined. Note that none of the index children were placed into OHC 15 or 17 years after the death of the mother, or 17 years after the death of the father. Figure includes only the first child of each mother within the study. 

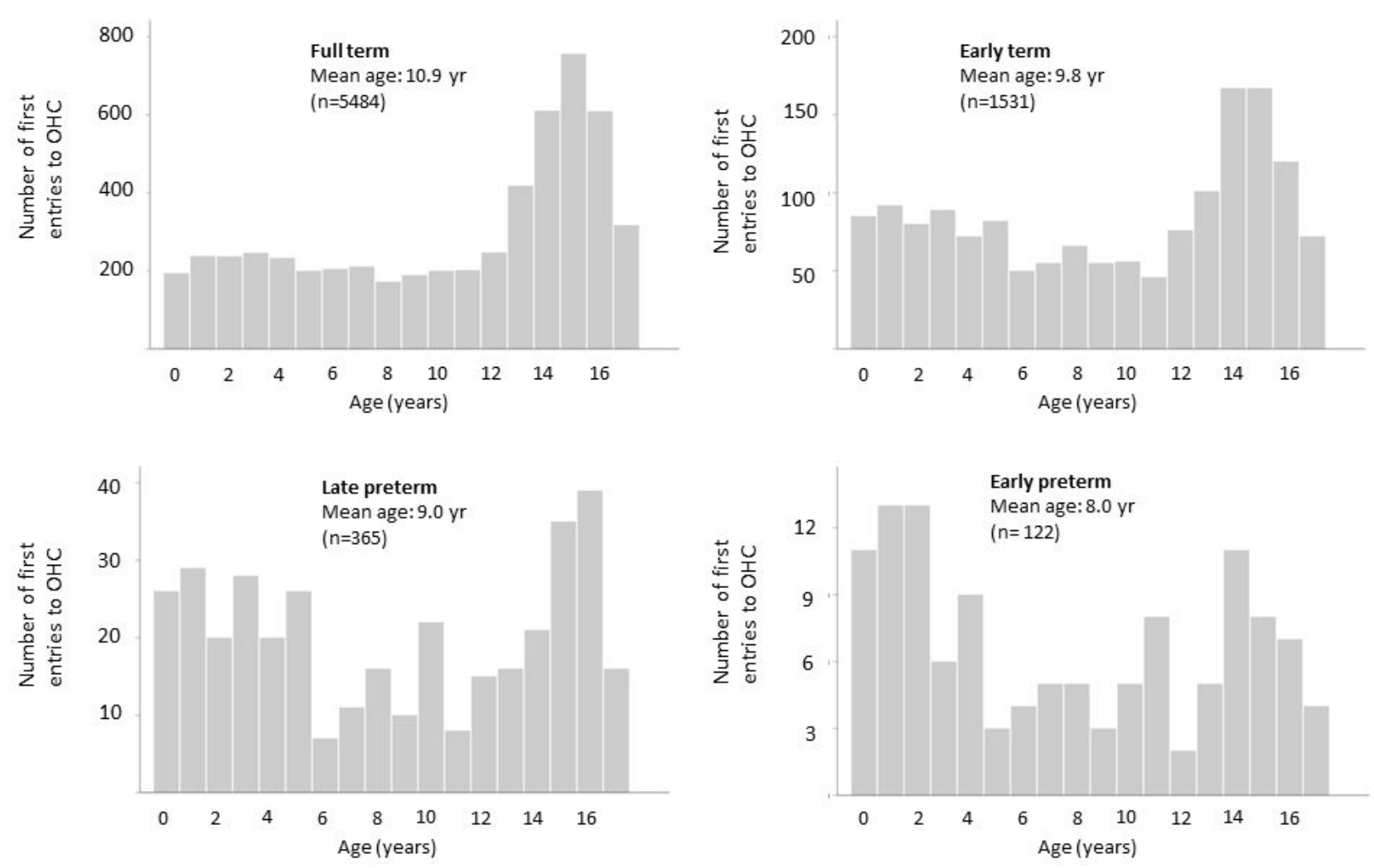

eFigure 3. The number of first entries to out-of-home care (OHC) by the age (years) of the index child within different gestational age categories. Figure covers all index children within the cohort (a total of 7870 first entries, of which 368 were those of born post term). 

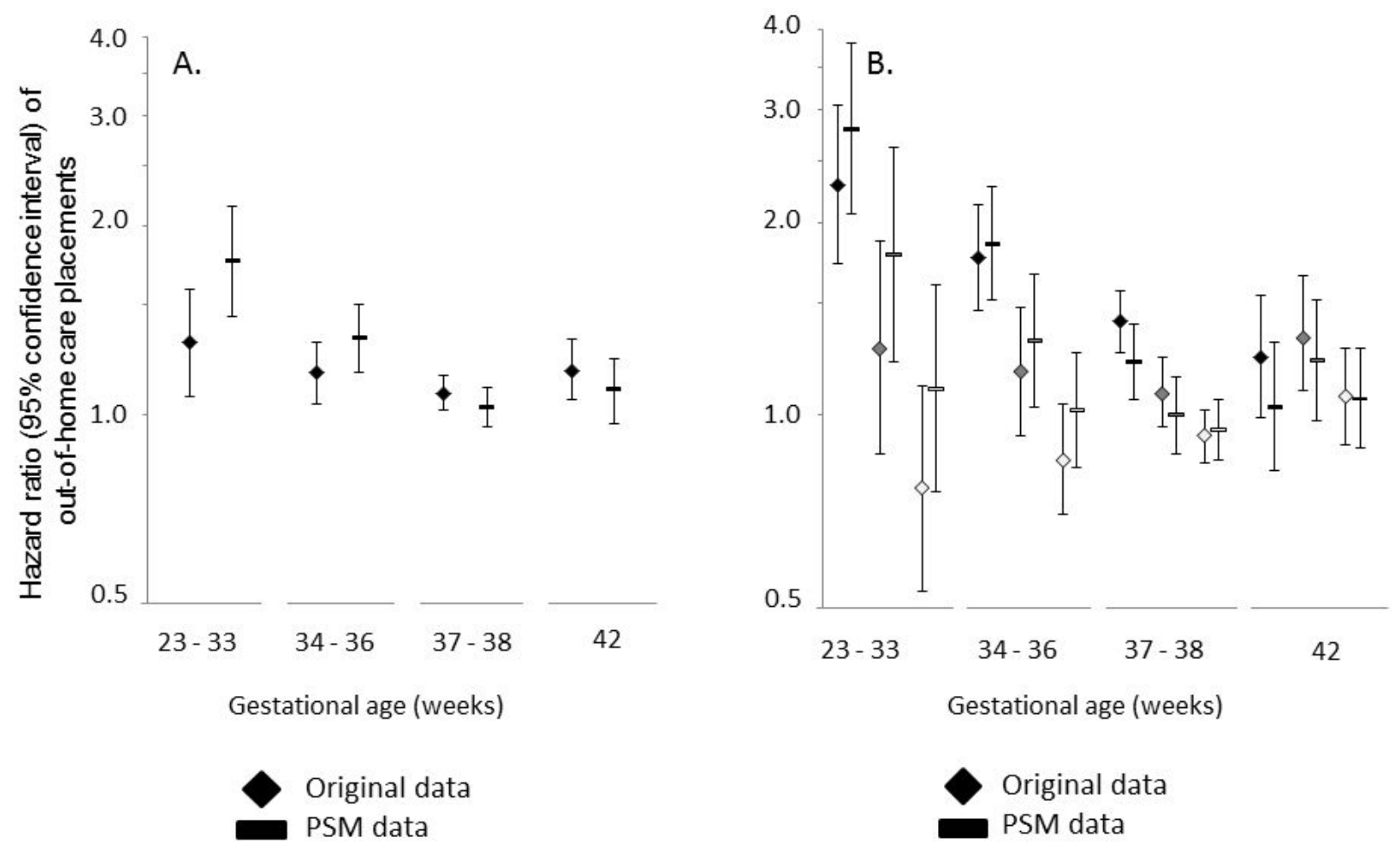

Age at 1st entry:

0 to $5 \mathrm{yr}$

$\square 6$ to $12 \mathrm{yr}$

13 to17 yr

eFigure 4. Comparisons of the results of the main analyses (original data) and the results of the analyses using propensity score matched (PSM) data. Only the first child of each mother within the cohort is included. Figure A illustrates the overall hazard ratios (95\% confidence intervals) for outof-home care (OHC) placement(s) and figure B presents hazard ratios (95\% confidence intervals) for OHC placement at certain age categories ( $0-5$ years of age; $6-12$ years of age; $13-17$ years of age) of the index child at first entry. 


\section{SUPPLEMENTARY TABLES:}


eTable 1. Components of the aggregate variable referred to as Alcohol and/or Substance Abuse

\begin{tabular}{|c|c|c|}
\hline Diagnosis & ICD-9 codes & ICD-8 codes \\
\hline \multicolumn{3}{|l|}{ Mental and behavioral disorders due to use of; } \\
\hline Alcohol-Acute intoxication & $3050 \mathrm{~A}$ & $980.00-01$ \\
\hline Alcohol - Other & $\begin{array}{l}\text { 2910A, 2911A, 2913A, 2918A, } \\
3039 X\end{array}$ & $\begin{array}{l}291.00-99 \\
303.00-99\end{array}$ \\
\hline Opioids & $\begin{array}{l}\text { 2920A, 2921B, 2928B, 2928D, } \\
\text { 2928X, 3040A, 3055A }\end{array}$ & $\begin{array}{l}304.00-01 \\
965.00\end{array}$ \\
\hline Cannabinoids & $\begin{array}{l}\text { 2920A, 2921B, 2928B, 2928D, } \\
\text { 2928X, 3043A, 3052A }\end{array}$ & 304.50 \\
\hline Sedatives or hypnotics & $\begin{array}{l}\text { 2054A, 2129B, 2920A, 2928B, } \\
\text { 2928D, 2928X, 3041A }\end{array}$ & $304.20-30$ \\
\hline Cocaine & $\begin{array}{l}\text { 2920A, 2921B, 2928B, 2928D, } \\
\text { 2928X, 3056A }\end{array}$ & 304.40 \\
\hline Other stimulants & $\begin{array}{l}\text { 2920A, 2921B, 2928B, 2928D, } \\
\text { 2928X, 3049X, 3059X }\end{array}$ & $304.60,970.00$ \\
\hline Hallucinogens & $\begin{array}{l}2921 \mathrm{~B}, 2928 \mathrm{D}, 2928 \mathrm{X}, 3045 \mathrm{~A}, \\
3053 \mathrm{~A}\end{array}$ & 304.70 \\
\hline Tobacco & 2920A, 3051A & . \\
\hline Volatile solvents & $\begin{array}{l}\text { 2920A, 2921B, 2928A, 2928X, } \\
\text { 2940A, 3046A, 3059X }\end{array}$ & . \\
\hline Multiple drugs and other psychoactive substances & $\begin{array}{l}\text { 2920A, 2921B, 2928B, 2928X, } \\
\text { 2940A, 3049X, 3059X }\end{array}$ & $304.88-99$ \\
\hline Alcoholic polyneuropathy & $3575 \mathrm{~A}$ & . \\
\hline Alcoholic cardiomyopathy & $4255 \mathrm{~A}$ & . \\
\hline Alcoholic gastritis & $5353 \mathrm{~A}$ & . \\
\hline Alcoholic liver disease & 5710A, 5711A, 5712A, 5713X & $571.00-01$ \\
\hline Poisoning by narcotics and hallucinogens & $\begin{array}{l}\text { 9650B, 9650E, 9650X, 9696A, } \\
9697 X, 9698 X\end{array}$ & $971.00-10$ \\
\hline $\begin{array}{l}\text { Poisoning by other and unspecified drugs, } \\
\text { medicaments and biological substances }\end{array}$ & $9779 X$ & $\begin{array}{l}970.10,970.90 \\
970.98-99\end{array}$ \\
\hline $\begin{array}{l}\text { Toxic effect of alcohol, including alcohols other than } \\
\text { ethyl-alcohol }\end{array}$ & 9800A, 9801A, 9802A & $980.00-99$ \\
\hline Toxic effect of tobacco and nicotine & . & . \\
\hline
\end{tabular}


eTable 2. The hazard ratios (HR) (95\% confidence intervals (CI)) for out-of-home care (OHC) placement by the gestational age ${ }^{\mathrm{a}}$ of the index child. The effect of parental death. The follow-up period begins at the birth of the index child. Only the first child of each mother within the cohort is included.

\begin{tabular}{|c|c|c|c|c|c|c|}
\hline $\begin{array}{l}\text { Gestational age } \\
\text { category, } \mathrm{n}\end{array}$ & $\begin{array}{c}\text { Early Preterm } \\
23 \text { to } 33 \text { weeks } \\
1965\end{array}$ & $\begin{array}{c}\text { Late Preterm } \\
34 \text { to } 36 \text { weeks } \\
6359\end{array}$ & $\begin{array}{c}\text { Early Term } \\
37 \text { to } 38 \text { weeks } \\
32987\end{array}$ & $\begin{array}{c}\text { Full Term } \\
39 \text { to } 41 \text { weeks } \\
143481\end{array}$ & $\begin{array}{l}\text { Post Term } \\
42 \text { weeks } \\
8220\end{array}$ & $\begin{array}{c}\text { Total } \\
23 \text { to } 42 \text { weeks } \\
193012\end{array}$ \\
\hline Placed into $\mathrm{OHC}, \mathrm{n}(\%)$ & $107(5.4)$ & $304(4.8)$ & $1241(3.8)$ & $4582(3.2)$ & $328(4.0)$ & $6562(3.4)$ \\
\hline $\begin{array}{l}\text { Mother died before first } \\
\text { placement, } \mathrm{n}(\%)^{\mathrm{b}}\end{array}$ & $5(4.7)$ & $9(3.0)$ & $41(3.3)$ & $108(2.4)$ & $5(1.5)$ & $168(2.6)$ \\
\hline $\begin{array}{l}\text { Father died before first } \\
\text { placement, } \mathrm{n}(\%)^{\mathrm{c}}\end{array}$ & $3(3.2)$ & $20(7.1)$ & $65(5.6)$ & $264(6.1)$ & $13(4.2)$ & $365(5.9)$ \\
\hline Model & $\operatorname{HR}(95 \% \mathrm{CI})$ & $\operatorname{HR}(95 \% \mathrm{CI})$ & $\operatorname{HR}(95 \% \mathrm{CI})$ & & $\operatorname{HR}(95 \% \mathrm{CI})$ & \\
\hline $0 \mathrm{~s}$ & $1.98(1.63,2.40)$ & $1.50(1.34,1.69)$ & $1.18(1.11,1.26)$ & 1.00 (Reference) & $1.22(1.09,1.37)$ & . \\
\hline $1^{\mathrm{b}}$ & $1.98(1.60,2.31)$ & $1.48(1.32,1.66)$ & $1.18(1.11,1.25)$ & 1.00 (Reference) & $1.23(1.10,1.37)$ & . \\
\hline $2^{c}$ & $1.84(1.50,2.26)$ & $1.49(1.32,1.68)$ & $1.17(1.09,1.25)$ & 1.00 (Reference) & $1.21(1.08,1.36)$ & . \\
\hline
\end{tabular}

a) Completed weeks' gestation.

b) Mothers without data from the Central Population Register (CPR); 21 (0.0\%).

c) Information on fatherhood not registered to the Central Population Register; 2920 (1.3\%).

Model 0s: Unadjusted model, stratified by the year of birth of the index child and by the maternal socioeconomic position at the birth of the index child.

Model 1: Model 0s + adjusted for time-dependent covariate of maternal death

Model 2: Model 0s + adjusted for time-dependent covariate of paternal death 
eTable 3. Characteristics of all index children $(N=226460)$ and their biological mothers $(\mathrm{N}=226439)$, and registered fathers $(\mathrm{N}=223540)$ by the gestational age category of the index child.

\begin{tabular}{|c|c|c|c|c|c|c|}
\hline & $\begin{array}{c}\text { Early Preterm } \\
23 \text { to } 33 \text { weeks }\end{array}$ & $\begin{array}{c}\text { Late Preterm } \\
34 \text { to } 36 \text { weeks }\end{array}$ & $\begin{array}{c}\text { Early Term } \\
37 \text { to } 38 \text { weeks }\end{array}$ & $\begin{array}{c}\text { Full Term } \\
39 \text { to } 41 \text { weeks }\end{array}$ & $\begin{array}{l}\text { Post Term } \\
42 \text { weeks }\end{array}$ & $\begin{array}{c}\text { Total Cohort } \\
23 \text { to } 42 \text { weeks }\end{array}$ \\
\hline Index children, $\mathrm{n}$ & 2237 & 7285 & 38938 & 168726 & 9274 & 226460 \\
\hline Length of gestation; weeks, mean (SD) & $30.7(2.8)$ & $35.9(0.8)$ & $38.2(0.5)$ & $40.3(0.8)$ & $42.2(0.2)$ & $39.8(1.7)$ \\
\hline Male, $\mathrm{n}(\%)$ & $1271(56.8)$ & $4011(55.1)$ & $20590(52.9)$ & $85394(50.6)$ & $4776(51.5)$ & $116042(51.2)$ \\
\hline Birthweight; g, mean (SD) & $1566(560)$ & $2741(486)$ & $3345(473)$ & $3682(459)$ & $3858(464)$ & $3580(546)$ \\
\hline Birthweight SD score, mean (SD) & $-0.27(1.57)$ & $-0.22(1.33)$ & $-0.01(1.16)$ & $0.02(1.02)$ & $-0.03(1.01)$ & $0.00(1.06)$ \\
\hline Small for gestational age; SGA, n (\%) & $332(14.8)$ & $684(9.4)$ & $1515(3.9)$ & $3371(2.0)$ & $217(2.3)$ & $6119(2.7)$ \\
\hline Severe infant morbidity, $\mathrm{n}(\%)^{\mathrm{a}}$ & $419(18.7)$ & $198(2.7)$ & $322(0.8)$ & $1205(0.7)$ & $88(0.9)$ & $2232(1.0)$ \\
\hline Developmental disorder or/and Intellectual disability, $\mathrm{n}(\%)$ & $58(2.6)$ & $62(0.9)$ & $236(0.6)$ & $842(0.5)$ & $60(0.6)$ & $1258(0.6)$ \\
\hline Cerebral palsy, $\mathrm{n}(\%)$ & $198(8.9)$ & $48(0.7)$ & $97(0.2)$ & $298(0.2)$ & $21(0.2)$ & $662(0.3)$ \\
\hline Died during follow-up, n (\%) & $410(18.3)$ & $166(2.3)$ & $327(0.8)$ & $934(0.6)$ & $50(0.5)$ & $1887(0.8)$ \\
\hline One or more major anomalies, $\mathrm{n}(\%)$ & $134(6.0)$ & $227(3.1)$ & $648(1.7)$ & $1735(1.0)$ & $101(1.1)$ & $2845(1.3)$ \\
\hline Urban location of birth, $\mathrm{n}(\%)$ & $1288(57.6)$ & $4034(55.4)$ & $21216(54.5)$ & $92332(54.7)$ & $5402(58.2)$ & $124272(54.9)$ \\
\hline Placed into OHC before the end of follow-up, $\mathrm{n}(\%)$ & $122(5.5)$ & $365(5.0)$ & $1531(3.9)$ & $5484(3.3)$ & $368(4.0)$ & $7870(3.5)$ \\
\hline Age at first OHC placement; years, mean (SD) & $8.0(5.7)$ & $9.0(5.8)$ & $9.8(5.5)$ & $10.9(5.3)$ & $10.5(5.2)$ & $10.5(5.4)$ \\
\hline Information on fatherhood not registered to CPR, $\mathrm{n}(\%)$ & $152(6.8)$ & $188(2.6)$ & $539(1.4)$ & $1903(1.1)$ & $138(1.5)$ & $2920(1.3)$ \\
\hline One parent died before the end of follow-up, n (\%) & $143(6.4)$ & $440(6.0)$ & $2038(5.2)$ & $7811(4.6)$ & $409(4.4)$ & $10841(4.8)$ \\
\hline Both parents died before the end of follow-up, $\mathrm{n}(\%)$ & $8(0.4)$ & $8(0.1)$ & $63(0.2)$ & $168(0.1)$ & $10(0.1)$ & $257(0.1)$ \\
\hline Emigrated before the end of follow-up, $\mathrm{n}(\%)$ & $9(0.4)$ & $35(0.5)$ & $199(0.5)$ & $856(0.5)$ & $51(0.5)$ & $1150(0.5)$ \\
\hline Mothers, $n$ & 2236 & 7284 & 38936 & 168711 & 9272 & 226439 \\
\hline Age at the birth of the index child; years, mean (SD) & $29.2(5.9)$ & $28.7(5.7)$ & $28.9(5.4)$ & $28.4(5.1)$ & $27.8(4.9)$ & $28.5(5.2)$ \\
\hline Less than 20 years, $n(\%)$ & $97(4.3)$ & $311(4.3)$ & $1203(3.1)$ & $4704(2.8)$ & $333(3.6)$ & $6648(2.9)$ \\
\hline 35 years or more, $n(\%)$ & $435(19.5)$ & $1252(17.2)$ & $6267(16.1)$ & $21203(12.6)$ & $914(9.9)$ & $30071(13.3)$ \\
\hline Age at the 1st OHC placement of the index child; years, mean (SD) & $34.9(8.3)$ & $36.5(8.5)$ & $36.7(8.3)$ & $37.3(7.7)$ & $36.5(7.5)$ & $37.1(7.9)$ \\
\hline Unmarried, $\mathrm{n}(\%)^{\mathrm{b}}$ & $644(29.3)$ & $1857(25.7)$ & $8102(20.9)$ & $34864(20.8)$ & $2357(25.5)$ & $47824(21.2)$ \\
\hline Smoked during pregnancy, $\mathrm{n}(\%)$ & $461(21.5)$ & $1359(19.1)$ & $6178(16.2)$ & $24486(14.8)$ & $1504(16.5)$ & $33988(15.3)$ \\
\hline
\end{tabular}


Pregnancy disorder, $\mathrm{n}(\%)^{\mathrm{c}}$

Late onset of antenatal care, $\mathrm{n}(\%)^{\mathrm{d}}$

Mode of delivery, $\mathrm{n}(\%)$

Two or more previous children, $\mathrm{n}(\%)^{\mathrm{e}}$

Previous IBI length $<18$ months, $\mathrm{n}(\%)$

Subsequent IBI length $<18$ months, $\mathrm{n}(\%)$

History of alcohol and/or substance misuse, $\mathrm{n}(\%)^{\mathrm{f}}$

History of any psychiatric disorder, $\mathrm{n}(\%)^{\mathrm{g}}$

Any psychiatric disorder prior to the $18^{\text {th }}$ birthday of the index child, $n$ $(\%)^{\mathrm{h}}$

Died before the first OHC placement of the index child, $\mathrm{n}(\%)$

Died during follow-up, $\mathrm{n}(\%)$

Socioeconomic position; SEP, $\mathrm{n}(\%)$

\section{Fathers, n}

Age at the birth of the index child; years, mean (SD)

$$
\text { Less than } 20 \text { years, } n(\%)
$$

35 years or more, $n(\%)$

Age at the first $\mathrm{OHC}$ placement of the child; years, mean (SD)

Died before the first OHC placement of the index child, $\mathrm{n}(\%)$

Died during follow-up, $\mathrm{n}(\%)$

Socioeconomic position; SEP, n (\%)

Higher official

Lower official

Manual worker

$\begin{array}{cc}551(24.6) & 1510(20.7) \\ 51(2.4) & 209(2.9) \\ \cdot & \cdot \\ 1111(49.7) & 5242(72.0) \\ 13(0.6) & 156(2.1) \\ 1112(49.7) & 1886(25.9) \\ 544(24.3) & 1755(24.1) \\ 186(15.5) & 497(12.8) \\ 216(19.1) & 531(13.4) \\ 51(2.3) & 114(1.6) \\ 84(3.9) & 204(2.8)\end{array}$

$213(9.5)$

$6(5.0)$

$67(3.0)$

.

$323(14.5)$

$782(35.2)$

$584(26.3)$

$531(23.9)$

2085

$31.9(6.5)$

$30(1.4)$

$605(29.0)$

$38.9(9.9)$

$3(2.8)$

$84(4.0)$

$11(19.8)$

346 (16.7)

895 (43.2)

572 (7.9)

$11(3.0)$

$155(2.1)$

$1181(16.3)$

$2661(36.8)$

$1666(23.0)$

7097

$31.6(6.2)$

$79(1.1)$

1908 (26.9)

$39.7(9.1)$

$21(6.2)$

293 (4.1)

$1189(16.9)$

2998 (42.6)

\section{7 (16.3) \\ 624 (1.6) \\ .}

30472 (78.3)

$976(2.5)$

7488 (19.2)

10792 (27.7)

$2540(10.6)$

2362 (11.3)

529 (1.4)

$980(2.5)$

$1724(23.8)$

$1415(20.1)$

2645 (6.8)

50 (3.3)

$590(1.5)$

$6774(17.5)$

14581 (37.6)

$9126(23.5)$

8288 (21.4)

38399

$31.7(6.0)$

$276(0.7)$

$10228(26.6)$

$40.2(8.7)$

$83(5.8)$

$1511(3.9)$

8270 (21.7)

$6853(18.0)$

\section{$13262(7.9)$}

1823 (1.1)

$431(4.6)$

133 (1.4)

$142615(84.5) \quad 7235(78.0)$

$6716(4.0)$

$19379(11.5)$

$41841(24.8)$

$9425(9.2)$

$10247(10.6)$

$1718(1.0)$

$3166(1.9)$

9551 (5.7)

15607 (40.9)

\section{$130(2.4)$}

2018 (1.2)

$29397(17.5)$

64469 (38.4)

38832 (23.1)

$35273(21.3)$

166823

$31.3(5.7)$

$1091(0.7)$

$38982(23.4)$

$40.9(8.4)$

$318(6.1)$

$5961(3.6)$

35801 (21.6)

$30041(18.1)$

$68101(41.1)$
$554(6.0)$

$1483(16.0)$

$1702(18.4)$

385 (8.9)

$644(10.9)$

$103(1.1)$

$181(2.0)$

$564(6.1)$

$5(1.4)$

$100(1.1)$

$484(16.1)$

3550 (38.5)

$2212(24.0)$

1985 (21.5)

9136

$30.9(5.7)$

$73(0.8)$

1967 (21.5)

$40.2(8.8)$

$14(4.0)$

319 (3.5)

$1893(20.9)$

$1613(17.8)$

3689 (40.7)
$22111(9.8)$

2840 (1.3)

186675 (82.4)

8415 (3.7)

$31348(13.8)$

56634 (25.0)

$13033(9.6)$

$14000(10.9)$

2515 (1.1)

4615 (2.0)

$13545(6.0)$

202 (2.6)

2930 (1.3)

39159 (17.4)

86043 (38.2)

52478 (23.3)

47743 (21.2)

223540

$31.4(5.8)$

$1549(0.7)$

$53690(24.0)$

40.7 (8.5)

439 (5.9)

$8168(3.7)$

47790 (21.5)

40042 (18.0)

91290 (41.1) 


$$
\text { Other }^{i} \quad 421(20.3)
$$

OHC - out-of-home care; CPR - Central Population Register

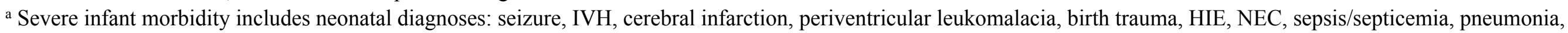
primary atelectasis, PDA, IRDS, and respiratory failure of the newborn. Composition of this covariate is presented in detail elsewhere. ${ }^{20}$

${ }^{b}$ Maternal marital status at the birth of the index child.

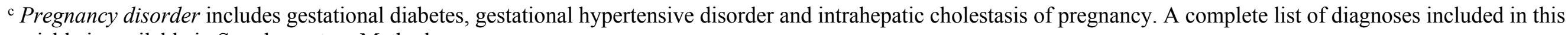
variable is available in Supplementary Methods.

d First appointment to the antenatal clinic after 22 completed weeks of gestation.

e Biological or adoptive.

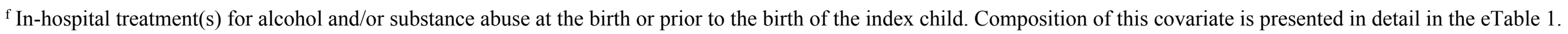

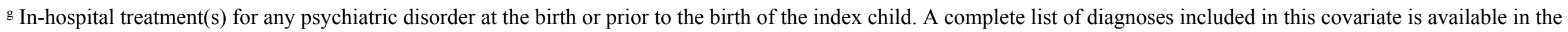
Supplementary Methods.

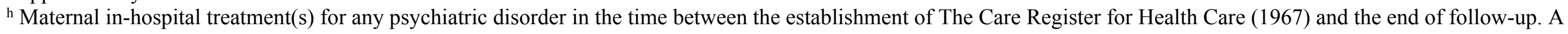
complete list of diagnoses included in this covariate is available in the Supplementary Methods.

${ }^{i}$ Other includes entrepreneurs, farmers, students, pensioners, unemployed, housewives and mothers or fathers with unclassifiable or unknown SEP.

The amount of missing data were $0.5 \%$ for maternal marital status, $1.9 \%$ for maternal smoking in pregnancy, $0.8 \%$ for the onset of antenatal care, $0.0 \%(n=1)$ for the mode of delivery, and $0.8 \%$ for maternal SEP. For paternal SEP the amount of missing data were $1.1 \%$.Data on other variables presented in this table are complete. Note that $40.1 \%$ of mothers did not have a previous child, and $43.2 \%$ of mothers did not have a subsequent one. 
eTable 4. The hazard ratios (HR) (95\% confidence intervals (CI)) for out-of-home care (OHC) placement by the gestational age of the index child. The followup period begins at the birth of the index child. Only the first child of each mother ${ }^{b}(N=193$ 012) within the cohort is included.

\begin{tabular}{|c|c|c|c|c|c|c|}
\hline $\begin{array}{c}\text { Gestational age } \\
\text { category, } \mathrm{n}\end{array}$ & $\begin{array}{c}\text { Early Preterm } \\
23 \text { to } 33 \text { weeks } \\
1965\end{array}$ & $\begin{array}{c}\text { Late Preterm } \\
34 \text { to } 36 \text { weeks } \\
6359\end{array}$ & $\begin{array}{c}\text { Early Term } \\
37 \text { to } 38 \text { weeks } \\
32987\end{array}$ & $\begin{array}{c}\text { Full Term } \\
39 \text { to } 41 \text { weeks } \\
143481\end{array}$ & $\begin{array}{l}\text { Post Term } \\
42 \text { weeks } \\
8220\end{array}$ & $\begin{array}{c}\text { Total } \\
23 \text { to } 42 \text { weeks } \\
193012\end{array}$ \\
\hline $\begin{array}{c}\text { Placed into } \mathrm{OHC}, \\
\mathrm{n}(\%)\end{array}$ & $106(5.4)$ & $304(4.8)$ & $1241(3.8)$ & $4582(3.2)$ & $328(4.0)$ & $6561(3.4)$ \\
\hline Model & HR $(95 \%$ CI) & HR (95\% CI) & HR $(95 \%$ CI) & & HR $(95 \%$ CI) & \\
\hline 0 & $2.11(1.74,2.56)$ & $1.54(1.37,1.73)$ & $1.19(1.12,1.26)$ & 1.00 (Reference) & $1.26(1.13,1.41)$ & . \\
\hline $0 \mathrm{~s}$ & $1.98(1.63,2.40)$ & $1.50(1.34,1.69)$ & $1.18(1.11,1.26)$ & 1.00 (Reference) & $1.22(1.09,1.37)$ & . \\
\hline 1 & $1.80(1.48,2.18)$ & $1.38(1.23,1.55)$ & $1.17(1.10,1.25)$ & 1.00 (Reference) & $1.16(1.04,1.30)$ & . \\
\hline 2 & $1.64(1.35,1.99)$ & $1.28(1.14,1.44)$ & $1.14(1.07,1.21)$ & 1.00 (Reference) & $1.16(1.04,1.30)$ & . \\
\hline 3 & $1.63(1.34,1.98)$ & $1.30(1.15,1.46)$ & $1.13(1.06,1.20)$ & 1.00 (Reference) & $1.18(1.05,1.32)$ & . \\
\hline 4 & $1.47(1.21,1.78)$ & $1.25(1.11,1.40)$ & $1.11(1.04,1.18)$ & 1.00 (Reference) & $1.20(1.07,1.34)$ & . \\
\hline 5 & $1.32(1.08,1.60)$ & $1.18(1.05,1.33)$ & $1.09(1.02,1.16)$ & 1.00 (Reference) & $1.19(1.07,1.33)$ & . \\
\hline 6 & $1.31(1.07,1.59)$ & $1.17(1.04,1.31)$ & $1.08(1.02,1.16)$ & 1.00 (Reference) & $1.18(1.06,1.32)$ & . \\
\hline
\end{tabular}

a Completed weeks' gestation.

${ }^{\mathrm{b}}$ Mothers without data from the Central Population Register (CPR); 21 (0.0\%).

Model 0: Unadjusted model.

Model 0s: Unadjusted model, stratified by the year of birth of the index child and by the maternal socioeconomic position at the birth of the index child.

Model 1: Model 0s + adjusted for the maternal age and marital status at the birth of the index child.

Model 2: Model $1+$ adjusted for maternal smoking in pregnancy and late onset of antenatal care

Model 3: Model $2+$ adjusted for the number of previous maternal live born children, previous maternal interbirth interval and for the urban location of the birth of the index child.

Model 4: Model $3+$ adjusted for the time-dependent variable of any maternal psychiatric disorder.

Model 5: Model 4 + adjusted for the smallness for gestational age status (SGA), developmental disorder or intellectual disability, cerebral palsy, major anomaly and the sex of the index child.

Model 6: Model $5+$ adjusted for the paternal socioeconomic position and age at the birth of index child 
eTable 5. Univariate association (hazard ratios (HR) and 95\% confidence intervals (CIs)) between the individual covariates and likelihood for out-of-home care $(\mathrm{OHC})$ placement.

Independent effect of covariates

The year of birth of the Index child (1987 versus 1988 or 1989 or 1990)

HR $(95 \% \mathrm{CI})$

$19881.05(0.98,1.18)$

$19891.15(1.08,1.22)$

$19901.23(1.15,1.31)$

$1.04(0.99,1.08)$

Index child's sex (boy vs girl)

$2.72(2.49,2.98)$

Small for gestational age; SGA (yes)

$4.33(3.73,5.04)$

Developmental disorder and/or Intellectual disability; (yes)

$1.26(1.03,1.56)$

Severe infant morbidity $(y e s)^{\mathrm{a}}$

$2.46(1.88,3.24)$

Cerebral palsy (yes)

$2.69(2.35,3.08)$

One or more major anomalies (yes)

$1.90(1.81,1.99)$

Urban location of birth (yes)

$0.92(0.92,0.93)$

Maternal age at index child's birth (20 to 34 years vs 19 years or less or 35 years or more)

19 years or less $4.21(3.92,4.53)$

35 years or more $0.91(0.85,0.98)$

Information on fatherhood not registered to the Central Population Register (yes)

$5.53(5.02,6.09)$

Maternal marital status at index child's birth (unmarried vs married)

$3.60(3.44,3.76)$

Smoking during pregnancy (yes)

$4.73(4.52,4.94)$

Pregnancy disorder $(y e s)^{\mathrm{b}}$

$0.95(0.88,1.02)$

Late onset of antenatal care (yes)

$3.21(2.92,3.53)$

Mode of delivery (spontaneous vaginal vs instrumental or cesarean section)

Instrumental $0.78(0.68,0.89)$

Cesarean section $1.03(0.97,1.10)$

The number of previous maternal children ( none vs one or two or more)

Previous interbirth interval length $<18$ months (yes)

One $0.86(0.82,0.91)$

Two or more $1.11(1.05,1.17)$

$1.71(1.58,1.85)$

Subsequent interbirth interval length $>18$ months (yes)

$1.46(1.35,1.59)$

Maternal alcohol and/or substance abuse $(\text { yes })^{\mathrm{c}}$

$8.75(8.06,9.51)$

Maternal any psychiatric disorder $(y e s)^{\mathrm{d}}$

$8.21(7.68,8.77)$

Maternal socioeconomic position (lower official vs higher official or manual worker or other)

Higher official $0.41(0.36,0.46)$

Manual worker $2.28(2.15,2.43)$

Other $3.39(3.20,3.59)$

Paternal age at index child's birth

$0.97(0.97,0.98)$

Paternal age at index child's birth (20 to 34 years vs. 19 years or less or 35 years or more)

19 years or less $5.01(4.39,5.72)$

35 years or more $1.40(1.30,1.51)$

Paternal Socioeconomic position (lower official vs. higher official or manual worker or other)

Higher official $0.42(0.37,0.47)$

Manual worker $2.31(2.17,2.45)$

Other $3.30(3.11,3.50)$ 
a Severe infant morbidity includes neonatal diagnoses: seizure, IVH, cerebral infarction, periventricular leukomalacia, birth trauma, HIE, NEC, sepsis/septicaemia, pneumonia, primary atelectasis, PDA, IRDS and respiratory failure of the newborn. Composition of this covariate is presented in detail elsewhere. ${ }^{20}$

${ }^{\mathrm{b}}$ Pregnancy disorder includes gestational diabetes, gestational hypertensive disorders and intrahepatic cholestasis of pregnancy (ICP). Composition of this covariate is presented in detail in Supplementary Methods.

${ }^{c}$ Maternal in-hospital treated alcohol and/or substance abuse prior to or at the birth of the index child. Diagnoses and diagnose codes included in this covariate are available in eTable 1.

d Maternal in-hospital treatment(s) for any psychiatric disorder prior to or at the birth of the index child. A complete list of diagnoses included in this variable is available in the Supplementary Methods.

BPD - bronchopulmonary dysplasia; ICH - intrahepatic cholestasis of pregnancy; IRDS - infant respiratory distress syndrome; IVH - intraventricular hemorrhage; HIE - hypoxic ischemic encephalopathy; NEC - necrotizing enterocolitis; PDA - patent ductus arteriosus 
eTable 6. The hazard ratios (HR) (95\% confidence intervals (CI)) for out-of-home care (OHC) placement by the gestational age of the index child and by the age category of the index child at first $\mathrm{OHC}$ entry. The follow-up period begins at the birth of the index child. Only the first child of each mother ${ }^{b}(N=193012)$ within the cohort is included.

\begin{tabular}{|c|c|c|c|c|c|c|c|}
\hline \multirow{3}{*}{\multicolumn{2}{|c|}{ Gestational age category, $\mathrm{n}$}} & Early Preterm & Late Preterm & Early Term & Full Term & Post Term & Total \\
\hline & & 23 to 33 weeks & 34 to 36 weeks & 37 to 38 weeks & 39 to 41 weeks & 42 weeks & 23 to 42 weeks \\
\hline & & 1965 & 6359 & 32987 & 143481 & 8220 & 193012 \\
\hline \multicolumn{2}{|c|}{ Placed into OHC, n (\%) } & $106(5.4)$ & $304(4.8)$ & $1241(3.8)$ & $4582(3.2)$ & $328(4.0)$ & $6561(3.4)$ \\
\hline \multirow[t]{2}{*}{ Model } & Age at 1st entry (yrs) & $\operatorname{HR}(95 \% \mathrm{CI})$ & HR $(95 \% \mathrm{CI})$ & $\operatorname{HR}(95 \% \mathrm{CI})$ & & $\operatorname{HR}(95 \% \mathrm{CI})$ & \\
\hline & 0 to 5 & $3.63(2.73,4.82)$ & $2.33(1.93,2.81)$ & $1.55(1.38,1.73)$ & 1.00 (Reference) & $1.26(1.01,1.58)$ & . \\
\hline \multirow[t]{3}{*}{$0 \mathrm{~s}$} & 6 to 12 & $1.93(1.32,2.83)$ & $1.49(1.19,1.87)$ & $1.18(1.04,1.33)$ & 1.00 (Reference) & $1.40(1.14,1.72)$ & . \\
\hline & 13 to 17 & $1.13(0.78,1.63)$ & $1.08(0.89,1.31)$ & $1.00(0.91,1.10)$ & 1.00 (Reference) & $1.11(0.94,1.31)$ & . \\
\hline & 0 to 5 & $2.29(1.72,3.05)$ & $1.76(1.46,2.13)$ & $1.40(1.25,1.56)$ & 1.00 (Reference) & $1.23(0.99,1.54)$ & . \\
\hline \multirow[t]{2}{*}{6} & 6 to 12 & $1.27(0.87,1.87)$ & $1.17(0.93,1.47)$ & $1.08(0.96,1.23)$ & 1.00 (Reference) & $1.34(1.09,1.65)$ & . \\
\hline & 13 to 17 & $0.77(0.53,1.11)$ & $0.85(0.70,1.04)$ & $0.93(0.84,1.02)$ & 1.00 (Reference) & $1.07(0.90,1.27)$ & . \\
\hline
\end{tabular}

${ }^{a}$ Completed weeks' gestation.

${ }^{\mathrm{b}}$ Mothers without data from the Central Population Register (CPR); $21(0.0 \%)$

Model 0s: unadjusted model, stratified by the year of birth of the index child and by the maternal socioeconomic position at the birth of the index child.

Model 6: Model 0s + adjusted for the maternal age and marital status at the birth of the index child, maternal smoking in pregnancy, late onset of antenatal care, the number of previous maternal live born children, previous maternal interbirth interval, urban location of birth of the index child, the time-dependent covariate for any maternal psychiatric disorder, smallness for gestational age (SGA) status, developmental disorder or intellectual disability, cerebral palsy, major anomaly, the sex of the index child and paternal socioeconomic position and age at the birth of the index child. 
eTable 7. The hazard ratios (HR) (95\% confidence intervals (CI)) for out-of-home care (OHC) placement by the gestational age ${ }^{\mathrm{a}}$ of the index child. The follow-up period begins at four years of age of the index child. Only the first child of each mother ${ }^{b}(N=193$ 012) within the cohort is included.

\begin{tabular}{|c|c|c|c|c|c|c|}
\hline $\begin{array}{l}\text { Gestational age } \\
\text { category, } \mathrm{n}\end{array}$ & $\begin{array}{c}\text { Early Preterm } \\
23 \text { to } 33 \text { weeks } \\
1574\end{array}$ & $\begin{array}{c}\text { Late Preterm } \\
34 \text { to } 36 \text { weeks } \\
6147\end{array}$ & $\begin{array}{c}\text { Early Term } \\
37 \text { to } 38 \text { weeks } \\
32479\end{array}$ & $\begin{array}{c}\text { Full Term } \\
39 \text { to } 41 \text { weeks } \\
142009\end{array}$ & $\begin{array}{c}\text { Post Term } \\
42 \text { weeks } \\
8122 \\
\end{array}$ & $\begin{array}{c}\text { Total } \\
23 \text { to } 42 \text { weeks } \\
190331 \\
\end{array}$ \\
\hline $\begin{array}{l}\text { Placed into } \mathrm{OHC}, \mathrm{n} \\
(\%)\end{array}$ & $68(4.3)$ & $221(3.6)$ & $966(3.0)$ & $3829(2.7)$ & $272(3.3)$ & $5356(2.8)$ \\
\hline Model & HR (95\% CI) & HR (95\% CI) & HR (95\% CI) & & HR (95\% CI) & \\
\hline 0 & $1.63(1.28,2.07)$ & $1.35(1.18,1.54)$ & $1.11(1.03,1.19)$ & 1.00 (Reference) & $1.25(1.11,1.42)$ & . \\
\hline $0 \mathrm{~s}$ & $1.54(1.21,1.96)$ & $1.32(1.15,1.51)$ & $1.10(1.03,1.18)$ & 1.00 (Reference) & $1.22(1.08,1.38)$ & . \\
\hline 1 & $1.42(1.11,1.80)$ & $1.22(1.07,1.40)$ & $1.10(1.02,1.18)$ & 1.00 (Reference) & $1.16(1.03,1.31)$ & . \\
\hline 2 & $1.33(1.04,1.69)$ & $1.15(1.00,1.32)$ & $1.07(1.00,1.15)$ & 1.00 (Reference) & $1.16(1.03,1.31)$ & . \\
\hline 3 & $1.32(1.04,1.68)$ & $1.17(1.02,1.34)$ & $1.07(0.99,1.15)$ & 1.00 (Reference) & $1.18(1.04,1.33)$ & . \\
\hline 4 & $1.21(0.96,1.54)$ & $1.13(0.99,1.30)$ & $1.05(0.98,1.13)$ & 1.00 (Reference) & $1.19(1.05,1.35)$ & . \\
\hline 5 & $1.15(0.90,1.46)$ & $1.09(0.95,1.25)$ & $1.04(0.97,1.12)$ & 1.00 (Reference) & $1.19(1.05,1.34)$ & . \\
\hline 6 & $1.14(0.89,1.45)$ & $1.08(0.94,1.23)$ & $1.04(0.97,1.11)$ & 1.00 (Reference) & $1.18(1.04,1.33)$ & . \\
\hline
\end{tabular}

${ }^{a}$ Completed weeks' gestation.

${ }^{\mathrm{b}}$ Mothers without data from the Central Population Register (CPR); 21 (0.0\%).

Model 0: Unadjusted model.

Model 0s: Unadjusted model, stratified by the year of birth of the index child and by the maternal socioeconomic position at the birth of the index child.

Model 1: Model 0s + adjusted for the maternal age and marital status at the birth of the index child.

Model 2: Model 1 + adjusted for maternal smoking in pregnancy and late onset of antenatal care.

Model 3: Model $2+$ adjusted for the number of previous maternal live born children, previous maternal interbirth interval and for the urban location of the birth of the index child.

Model 4: Model 3 + adjusted for the time-dependent variable of any maternal psychiatric disorder.

Model 5: Model 4 + adjusted for the smallness for gestational age status (SGA), developmental disorder or intellectual disability, cerebral palsy, major anomaly and the sex of the index child.

Model 6: Model $5+$ adjusted for the paternal socioeconomic position and age at the birth of index child. 
eTable 8. The hazard ratios (HR) (95\% confidence intervals (CI)) for out-of-home care (OHC) placement by the gestational age of the index child and by the age category of the index child at first $\mathrm{OHC}$ entry. The follow-up period begins at four years of age of the index child. Only the first child of each mother ${ }^{b}(N=193$ 012) within the cohort is included.

\begin{tabular}{|c|c|c|c|c|c|c|c|}
\hline \multirow{3}{*}{\multicolumn{2}{|c|}{ Gestational age category, $\mathrm{n}$}} & Early Preterm & Late Preterm & Early Term & Full Term & Post Term & Total \\
\hline & & 23 to 33 weeks & 34 to 36 weeks & 37 to 38 weeks & 39 to 41 weeks & 42 weeks & 23 to 42 weeks \\
\hline & & 1574 & 6147 & 32479 & 142009 & 8122 & 190331 \\
\hline \multicolumn{2}{|c|}{ Placed into $\mathrm{OHC}, \mathrm{n}(\%)$} & $68(4.3)$ & $221(3.6)$ & $966(3.0)$ & $3829(2.7)$ & $272(3.3)$ & $5356(2.8)$ \\
\hline \multirow[t]{2}{*}{ Model } & Age at 1st entry (yrs) & $\operatorname{HR}(95 \% \mathrm{CI})$ & $\operatorname{HR}(95 \% \mathrm{CI})$ & $\operatorname{HR}(95 \% \mathrm{CI})$ & & $\operatorname{HR}(95 \% \mathrm{CI})$ & \\
\hline & 4 to 5 & $2.32(1.59,3.38)$ & $1.66(1.32,2.10)$ & $1.27(1.11,1.44)$ & 1.00 (Reference) & $1.39(1.11,1.73)$ & . \\
\hline \multirow[t]{3}{*}{ 0s } & 6 to 12 & $1.26(0.91,1.74)$ & $1.18(0.99,1.40)$ & $1.05(0.96,1.15)$ & 1.00 (Reference) & $1.18(1.01,1.37)$ & . \\
\hline & 13 to 17 & $1.49(0.56,4.01)$ & $1.27(0.72,2.21)$ & $0.98(0.73,1.32)$ & 1.00 (Reference) & $1.01(0.59,1.74)$ & . \\
\hline & 4 to 5 & $1.64(1.12,2.42)$ & $1.34(1.06,1.69)$ & $1.19(1.05,1.36)$ & 1.00 (Reference) & $1.35(1.08,1.69)$ & . \\
\hline \multirow[t]{2}{*}{6} & 6 to 12 & $0.94(0.68,1.30)$ & $0.96(0.81,1.15)$ & $0.99(0.90,1.08)$ & 1.00 (Reference) & $1.14(0.98,1.33)$ & . \\
\hline & 13 to 17 & $1.05(0.39,2.82)$ & $1.14(0.68,1.92)$ & $0.88(0.66,1.18)$ & 1.00 (Reference) & $0.91(0.53,1.56)$ & . \\
\hline
\end{tabular}

${ }^{\text {a }}$ Completed weeks' gestation.

${ }^{\mathrm{b}}$ Mothers without data from the Central Population Register (CPR); $21(0.0 \%)$

Model 0s: Unadjusted model, stratified by the year of birth of the index child and by the maternal socioeconomic position at the birth of the index child.

Model 6: Model 0s + adjusted for the maternal age and marital status at the birth of the index child, maternal smoking in pregnancy, late onset of antenatal care, the number of previous maternal live born children, previous maternal interbirth interval, the urban location of the birth of the index child, the time-dependent covariate for any maternal psychiatric disorder, smallness for gestational age status (SGA), developmental disorder or intellectual disability, cerebral palsy, major anomaly, the sex of the index child and the paternal socioeconomic position and age at the birth of the index child. 
eTable 9. The hazard ratios (HR) (95\% confidence intervals (CI)) for out-of-home care (OHC) placement by the gestational age of the index child. The follow-up period begins at the birth of the index child. Includes 226439 mother and child dyads ${ }^{b}$.

\begin{tabular}{|c|c|c|c|c|c|c|}
\hline $\begin{array}{c}\text { Gestational age } \\
\text { category, } \mathrm{n}\end{array}$ & $\begin{array}{c}\text { Early Preterm } \\
23 \text { to } 33 \text { weeks } \\
2236\end{array}$ & $\begin{array}{c}\text { Late Preterm } \\
34 \text { to } 36 \text { weeks } \\
7284\end{array}$ & $\begin{array}{c}\text { Early Term } \\
37 \text { to } 38 \text { weeks } \\
38936\end{array}$ & $\begin{array}{c}\text { Full Term } \\
39 \text { to } 41 \text { weeks } \\
168711\end{array}$ & $\begin{array}{c}\text { Post Term } \\
42 \text { weeks } \\
9272\end{array}$ & $\begin{array}{c}\text { Total } \\
23 \text { to } 42 \text { weeks } \\
226439\end{array}$ \\
\hline $\begin{array}{l}\text { Placed into } \\
\text { OHC, n }(\%)\end{array}$ & $121(5.4)$ & $365(5.0)$ & $1531(3.9)$ & $5484(3.3)$ & $368(4.0)$ & $7869(3.5)$ \\
\hline Model & HR (95\% CI) & HR (95\% CI) & HR (95\% CI) & & HR (95\% CI) & \\
\hline 0 & $2.08(1.74,2.49)$ & $1.59(1.43,1.77)$ & $1.22(1.15,1.29)$ & 1.00 (Reference) & $1.23(1.11,1.37)$ & . \\
\hline $0 \mathrm{~s}$ & $1.96(1.64,2.35)$ & $1.54(1.39,1.72)$ & $1.21(1.15,1.28)$ & 1.00 (Reference) & $1.20(1.08,1.33)$ & . \\
\hline 1 & $1.75(1.46,2.09)$ & $1.42(1.28,1.58)$ & $1.20(1.14,1.27)$ & 1.00 (Reference) & $1.13(1.01,1.25)$ & . \\
\hline 2 & $1.56(1.31,1.87)$ & $1.30(1.17,1.44)$ & $1.16(1.10,1.23)$ & 1.00 (Reference) & $1.13(1.01,1.25)$ & . \\
\hline 3 & $1.51(1.26,1.81)$ & $1.29(1.16,1.44)$ & $1.14(1.08,1.21)$ & 1.00 (Reference) & $1.15(1.04,1.28)$ & . \\
\hline 4 & $1.37(1.15,1.65)$ & $1.25(1.12,1.39)$ & $1.12(1.06,1.18)$ & 1.00 (Reference) & $1.16(1.04,1.29)$ & . \\
\hline 5 & $1.22(1.01,1.47)$ & $1.19(1.06,1.32)$ & $1.10(1.04,1.16)$ & 1.00 (Reference) & $1.16(1.04,1.29)$ & . \\
\hline 6 & $1.22(1.00,1.44)$ & $1.17(1.05,1.30)$ & $1.10(1.04,1.16)$ & 1.00 (Reference) & $1.15(1.03,1.27)$ & . \\
\hline
\end{tabular}

${ }^{a}$ Completed weeks' gestation

${ }^{\mathrm{b}}$ Mothers without data from the Central Population Register (CPR); 21 (0.0\%).

Model 0: Unadjusted model.

Model 0s: Unadjusted model, stratified by the year of birth of the index child and by the maternal socioeconomic position at the birth of the index child.

Model 1: Model 0s + adjusted for the maternal age and marital status at the birth of the index child.

Model 2: Model 1 + adjusted for maternal smoking in pregnancy and late onset of antenatal care.

Model 3: Model $2+$ adjusted for the number of previous maternal live born children, previous maternal interbirth interval and for the urban location of the birth of the index child.

Model 4: Model 3 + adjusted for time-dependent variable of any maternal psychiatric disorder.

Model 5: Model 4 + adjusted for the smallness for gestational age (SGA) status, developmental disorder or intellectual disability, cerebral palsy, major anomaly and the sex of the index child.

Model 6: Model $5+$ adjusted for the paternal socioeconomic position and age at the birth of index child. 
eTable 10. The hazard ratios (HR) (95\% confidence intervals (CI)) for out-of-home care (OHC) placement by the gestational age of the index child and by the age category of the index child at first OHC entry. The follow-up period begins at the birth of the index child. Includes 226439 mother and child dyads ${ }^{b}$.

\begin{tabular}{|c|c|c|c|c|c|c|c|}
\hline \multirow{2}{*}{\multicolumn{2}{|c|}{ Gestational age category, $\mathrm{n}$}} & Early Preterm & Late Preterm & Early Term & Full Term & Post Term & Total \\
\hline & & 23 to 33 weeks & 34 to 36 weeks & 37 to 38 weeks & 39 to 41 weeks & 42 weeks & 23 to 42 weeks \\
\hline & & 2236 & 7284 & 38936 & 168711 & 9272 & 226439 \\
\hline \multicolumn{2}{|c|}{ Placed into OHC, n (\%) } & $121(5.4)$ & $365(5.0)$ & $1531(3.9)$ & $5484(3.3)$ & $368(4.0)$ & $7869(3.5)$ \\
\hline \multirow[t]{2}{*}{ Model } & Age at 1st entry (yrs) & $\operatorname{HR}(95 \% \mathrm{CI})$ & $\operatorname{HR}(95 \% \mathrm{CI})$ & $\operatorname{HR}(95 \% \mathrm{CI})$ & . & $\operatorname{HR}(95 \% \mathrm{CI})$ & . \\
\hline & 0 to 5 & $3.45(2.63,4.52)$ & $2.49(2.10,2.94)$ & $1.60(1.44,1.77)$ & 1.00 (Reference) & $1.22(0.99,1.50)$ & . \\
\hline \multirow[t]{3}{*}{$0 \mathrm{~s}$} & 6 to 12 & $1.94(1.36,2.77)$ & $1.44(1.16,1.78)$ & $1.23(1.10,1.38)$ & 1.00 (Reference) & $1.37(1.13,1.66)$ & . \\
\hline & 13 to 17 & $1.18(0.85,1.65)$ & $1.11(0.93,1.32)$ & $1.01(0.92,1.10)$ & 1.00 (Reference) & $1.10(0.94,1.29)$ & . \\
\hline & 0 to 5 & $2.08(1.58,2.73)$ & $1.81(1.53,2.15)$ & $1.41(1.28,1.57)$ & 1.00 (Reference) & $1.17(0.95,1.45)$ & . \\
\hline \multirow[t]{2}{*}{6} & 6 to 12 & $1.20(0.84,1.71)$ & $1.10(0.88,1.36)$ & $1.12(1.00,1.25)$ & 1.00 (Reference) & $1.30(1.07,1.58)$ & . \\
\hline & 13 to 17 & $0.75(0.54,1.05)$ & $0.86(0.72,1.02)$ & $0.92(0.84,1.00)$ & 1.00 (Reference) & $1.05(0.90,1.23)$ & . \\
\hline
\end{tabular}

${ }^{\text {a }}$ Completed weeks' gestation.

${ }^{\mathrm{b}}$ Mothers without data from the Central Population Register (CPR); 21 (0.0\%).

Model 0s: Unadjusted model, stratified by the year of birth of the index child and by maternal socioeconomic position at the birth of the index child.

Model 6: Model 0s + adjusted for the maternal age and marital status at the birth of the index child, maternal smoking in pregnancy, late onset of antenatal care, the number of previous maternal live born children, previous maternal interbirth interval, the urban location of the birth of the index child, the timedependent covariate for any maternal psychiatric disorder, smallness for gestational age (SGA) status, developmental disorder or intellectual disability, cerebral palsy, major anomaly, the sex of the index child and paternal socioeconomic position and age at the birth of the index child. 
eTable 11. The hazard ratios (HR) (95\% confidence intervals (CI)) for out-of-home care (OHC) placement by the gestational age of the index child. Propensity score matched data (a total of 115566 mother-child dyads). The follow-up period begins at the birth of the index child. Only the first child of each mother ( $N=$ 98 979) within the cohort is included.

\begin{tabular}{|c|c|c|c|c|c|c|}
\hline \multirow{3}{*}{$\begin{array}{l}\text { Gestational age } \\
\text { category, } \mathrm{n}\end{array}$} & Early Preterm & Late Preterm & Early Term & Full Term & Post Term & Total \\
\hline & 23 to 33 weeks & 34 to 36 weeks & 37 to 38 weeks & 39 to 41 weeks & 42 weeks & 23 to 42 weeks \\
\hline & 1919 & 6317 & 32927 & 49602 & 8214 & 98979 \\
\hline Placed into OHC, $\mathrm{n}(\%)$ & $99(5.2)$ & $297(4.7)$ & $1230(3.7)$ & $1797(3.6)$ & $326(4.0)$ & $3749(3.8)$ \\
\hline $0^{\mathrm{b}}$ & $1.76(1.44,2.15)$ & $1.33(1.17,1.50)$ & $1.03(0.96,1.11)$ & 1.00 (Reference) & $1.10(0.97,1.23)$ & \\
\hline
\end{tabular}

a) Completed weeks' gestation

b) Unadjusted model utilising the propensity score matched data. The propensity score was estimated with the following variables: maternal socioeconomic position at the birth of the index child, the birth year of the index child, the maternal age at the birth of the index child, the maternal marital status at the birth of the index child, maternal smoking in pregnancy, late onset of antenatal care, the number of previous maternal live born children, previous maternal interbirth interval, the urban location of the birth of the index child, any maternal psychiatric disorder prior the birth of the index child, smallness for gestational age (SGA) status of the index child, developmental disorder or intellectual disability of the child, cerebral palsy, major anomaly, the sex of the index child, the paternal socioeconomic position and paternal age at the birth of the index child. 
eTable 12. The hazard ratios (HR) $(95 \%$ confidence intervals (CI)) for out-of-home care (OHC) placement by the gestational age of the index child and by the age category of the index child at first OHC entry . Propensity score matched data (a total of 115566 mother-child dyads). The follow-up period begins at the birth of the index child. Only the first child of each mother $(N=98979)$ within the cohort is included.

\begin{tabular}{|c|c|c|c|c|c|c|}
\hline $\begin{array}{c}\text { Gestational age } \\
\text { category, } \mathrm{n}\end{array}$ & $\begin{array}{c}\text { Early Preterm } \\
23 \text { to } 33 \text { weeks } \\
1919\end{array}$ & $\begin{array}{c}\text { Late Preterm } \\
34 \text { to } 36 \text { weeks } \\
6317\end{array}$ & $\begin{array}{c}\text { Early Term } \\
37 \text { to } 38 \text { weeks } \\
32927\end{array}$ & $\begin{array}{c}\text { Full Term } \\
39 \text { to } 41 \text { weeks } \\
49602\end{array}$ & $\begin{array}{l}\text { Post Term } \\
42 \text { weeks } \\
8214\end{array}$ & $\begin{array}{c}\text { Total } \\
23 \text { to } 42 \text { weeks } \\
98979\end{array}$ \\
\hline Placed into $\mathrm{OHC}, \mathrm{n}(\%)$ & $99(5.2)$ & $297(4.7)$ & $1230(3.7)$ & $1797(3.6)$ & $326(4.0)$ & $3749(3.8)$ \\
\hline $\begin{array}{cc}\text { Age at 1st entry } \\
\text { Model } & (\mathrm{yrs})\end{array}$ & $\operatorname{HR}(95 \% \mathrm{CI})$ & $\operatorname{HR}(95 \% \mathrm{CI})$ & $\operatorname{HR}(95 \% \mathrm{CI})$ & & HR $(95 \%$ CI $)$ & \\
\hline 0 to 5 & $2.80(2.06,3.81)$ & $1.85(1.51,2.27)$ & $1.21(1.06,1.39)$ & 1.00 (Reference) & $1.03(0.82,1.30)$ & . \\
\hline 6 to 12 & $1.78(1.21,2.62)$ & $1.31(1.03,1.66)$ & $1.00(0.87,1.15)$ & 1.00 (Reference) & $1.22(0.98,1.51)$ & . \\
\hline 13 to 17 & $1.10(0.76,1.60)$ & $1.02(0.83,1.25)$ & $0.95(0.85,1.06)$ & 1.00 (Reference) & $1.06(0.89,1.27)$ & . \\
\hline
\end{tabular}

a) Completed weeks' gestation

b) Unadjusted model utilising propensity score matched data. The propensity score was estimated with the following variables: the maternal socioeconomic position at the birth of the index child, the birth year of the index child, the maternal age at the birth of the index child, maternal marital status at the birth of the index child, maternal smoking in pregnancy, late onset of antenatal care, the number of previous maternal live born children, previous maternal interbirth interval, the urban location of the birth of the index child, any maternal psychiatric disorder prior the birth of the index child, smallness for gestational age (SGA) status of the index child, developmental disorder or intellectual disability of the child, cerebral palsy, major anomaly, the sex of the index child, the paternal socioeconomic position and paternal age at the birth of the index child. 